\title{
A multi-method assessment of bone maintenance and loss in an Imperial Roman population: Implications for future studies of age-related bone loss in the past
}

\author{
Patrick Beauchesne $^{1}$ [D | Sabrina C. Agarwal ${ }^{2}$
}

${ }^{1}$ Department of Behavioral Sciences, University of Michigan, Dearborn, Michigan

${ }^{2}$ Department of Anthropology, University of California, Berkeley, California

\section{Correspondence}

Patrick Beauchesne, University of Michigan, Dearborn, 4012 CASL Building, 4901

Evergreen Road, Dearborn, MI 48128, USA.

Email: pbeauch@umich.edu

Funding information

Social Sciences and Humanities Research Council of Canada doctoral fellowship, Stahl research grant, COR UC Berkeley faculty grant.

\begin{abstract}
Objectives: One of the hallmarks of contemporary osteoporosis and bone loss is dramatically higher prevalence of loss and fragility in females post-menopause. In contrast, bioarchaeological studies of bone loss have found a greater diversity of age- and sex-related patterns of bone loss in past populations. We argue that the differing findings may relate to the fact that most studies use only a single methodology to quantify bone loss and do not account for the heterogeneity and complexity of bone maintenance across the skeleton and over the life course.

Methods: We test the hypothesis that bone mass and maintenance in trabecular bone sites versus cortical bone sites will show differing patterns of age-related bone loss, with cortical bone sites showing sex difference in bone loss that are similar to contemporary Western populations, and trabecular bone loss at earlier ages. We investigated this hypothesis in the Imperial Roman population of Velia using three methods: radiogrammetry of the second metacarpal $(N=71)$, bone histology of ribs $(N=70)$, and computerized tomography of trabecular bone architecture $(N=47)$. All three methods were used to explore sex and age differences in patterns of bone loss.

Results: The suite of methods utilized reveal differences in the timing of bone loss with age, but all methods found no statistically significant differences in age-related bone loss.

Discussion: We argue that a multi-method approach reduces the influence of confounding factors by building a reconstruction of bone turnover over the life cycle that a limited single-method project cannot provide. The implications of using multiple methods beyond studies of bone loss are also discussed.
\end{abstract}

\section{KEYWORDS}

bone histology, bone loss, bone mass, metacarpal radiogrammetry, trabecular architecture

\section{1 | INTRODUCTION}

Osteoporosis is currently one of the leading diseases affecting people over the age of 50 in contemporary Western societies. Osteoporosis is clinically defined as abnormal bone loss and its most severe form is accompanied by the presence of fragility fractures that occur with only minimal trauma (Birnbaum, 1992; Center \& Eisman, 1997; Melton, 2003; Mundy, 1995; Ross, Santora, \& Yates, 1999; Stini, 1995). A diagnosis of osteoporosis is given through the assessment of bone mineral density (BMD) determined by dual-energy X-ray absorptiometry
(DEXA) and are operationalized in terms of fracture risk (Center \& Eisman, 1997). Although clinicians work under these guidelines, defining osteoporosis is challenging and somewhat arbitrary as bone loss is a natural process of aging and thus differentiating normal processes from pathological bone loss can be difficult; it is a difference of degree and not of kind. Additionally, loss of bone mass itself does not necessarily equate with fracture (Frost, 2001; Heaney, 2003; Ross et al., 1999). Factors of bone quality, such as how bone is organized and distributed, and not simply how much bone is present, are also critical to understanding bone strength and fragility (Carballido-Gamio \& 
Majumdar, 2006; Fonseca et al., 2014 ; Kehoe, 2006). Consequently, osteoporosis also has multiple causal factors, and parsing out their respective roles is problematic.

In the United States, it is estimated that 10 million people have osteoporosis, while another 34 million suffer from osteopenia (low bone mass) (Becker, Killgore, \& Morrisey, 2010; Dempster, 2011). With an aging population, the problem is only worsening. It is projected that by 2020,61 million people in the United States will have either osteopenia or osteoporosis (Dempster, 2011). One of the hallmarks of the disease is that it affects over half of people over the age of 50 and that 80 percent of those who develop the condition will be female (NOF, 2010).

The principle medical and socio-economic costs of osteoporosis are related to fragility fractures. Sufferers of fragility fractures are commonly susceptible to post-operative infection and complications, venous thromboembolism, disabling pain, pneumonia, and general physical disability (Becker et al., 2010; Dempster, 2011). The social costs are often as high as the physical ones. After a serious fracture, many individuals suffer from psychological deterioration, depression, and face considerable strain on their relationships (Becker et al., 2010; Dempster, 2011). Unfortunately, the precursor to osteoporosis, osteopenia, is largely asymptomatic, so when fractures occur the financial and social costs arrive suddenly. Osteopenia is generally defined as a loss of BMD occurring at a greater rate than what is statistically normal (Mundy, 1995). Osteopenia itself is not strictly pathological in nature, but it does present a significant increase in the future risk of fragility fractures (Dempster, 2011; Mundy, 1995) and is thus a major health concern. In light of these societal costs, much more work remains to be done in order to fully understand the natural history of bone loss and fragility, and curtail the prevalence of osteoporosis in future generations.

It is now well established that osteoporosis is a heterogeneous disorder and that a suite of factors influence its development and manifestation. For example, physical activity, nutrition, hormonal status, and reproductive history have all been shown to be associated with osteoporosis risk (Christodoulou \& Cooper, 2003). Lifestyle factors such as smoking and alcohol consumption can also have an effect on bone health and fracture risk (Cummings et al., 1995; Seeman, 1996). While all of these factors play contributing roles in the etiology of the disease, their degree of influence is not consistent over the life course. The influence that physical activity has on bone growth, maintenance, and loss over the life course is a good example (Morris-Naumann \& Wark, 2014). For instance, the adolescent bone growth period is particularly sensitive to the effects of physical activity (Janz et al., 2014; Rauch, Bailey, Baxter-Jones, Mirwald, \& Faulkner, 2004). During this highly responsive period, elevated levels of physical activity allow for an increased deposition of bone mass to accumulate by young adulthood and increased peak bone mass, thus mediating some of the effects of bone loss later in life (Bonjour, Chevalley, \& Ferrari, 2007). Peak bone mass is defined as the maximum amount of bone volume obtained during growth (Center \& Eisman, 1997), and the consensus in the clinical literature is that peak bone mass is one of the more crucial factors in determining later osteoporotic and osteopenic risk. Failure to attain a high peak bone mass presents a greater fracture risk as fractures may occur earlier at the onset of age-related remodeling changes and associated reduced bone mass (Brickley \& Ives, 2008). Peak bone mass reaches its apex during the third decade of life and remains fairly constant until the fourth (Center \& Eisman, 1997), although the timing of peak bone mass may vary between individuals by up to a decade (Bonjour, Chevalley, Ammann, Slosman, \& Rizzoli, 2001; Orwoll, Belknap, \& Klein, 2001; Raisz \& Seeman, 2001). Peak bone mass is determined by a suite of factors including genetics, childhood health, nutrition, physical activity during growth and development, and sex steroids (Brickley \& Ives, 2008; Mundy, 1995). While mechanical strain and activity continue to influence bone formation into adulthood (Ruff, Holt, \& Trinkaus, 2006), the greatest impact of activity is largely limited to earlier periods in life (Pearson \& Lieberman, 2004).

Biological anthropologists have made numerous attempts to explore the historical trajectories and biocultural influences on pattern of bone growth, maintenance, and loss in past populations, often with the goal of contextualizing modern patterns. Although the study of bone loss in past populations has been investigated using a range of methods, the prevalence of the disease in the past ultimately remains unclear (Agarwal, 2008; Brickley \& Agarwal, 2003; Brickley \& Ives, 2008). While bone loss in adulthood is universal and has been shown in every study (Agarwal, 2008), typical patterns of postmenopausal bone loss seen in modern Western women are often not seen in past populations (Agarwal, 2012; Agarwal \& Grynpas, 1996, 2009; Glencross \& Agarwal, 2011; Grynpas, 2003; Nelson, Sauer, \& Agarwal., 2003; Robling \& Stout, 2004). For example, bone loss is often seen at younger ages and in both sexes (Agarwal, 2012; Agarwal \& Grynpas, 1996, 2009; Ekenman, Eriksson, \& Lindgren, 1995; Holck, 2007; Lees, Molleson, Arnett, \& Stevenson, 1993; Weaver, 1998). Bone loss with age is also often very similar between the sexes (Agarwal et al., 2004; Brickley, 2002; Cho \& Stout, 2003; Ekenman et al., 1995; Holck, 2007), a pattern that deviates from Western societies today. Fragility fractures in the past also seem to occur at far lower frequencies than in modern populations (Agarwal, 2008; Ives, Mant, de la Cova, \& Brickley, in press; Madimenos, 2015). This latter point is important as females today are at far greater risk for fracture than males (Agarwal, 2008). It is important to note however that Brickley and Agarwal (2003) caution that a number of confounding factors must be accounted for when assessing the prevalence of fragility fractures in the past. First, the lack of fragility fractures may be a reflection of the hidden heterogeneity in frailty of archaeological skeletal populations, where the individuals we observe in old age represent a "healthier" group that survived, and thus do not represent the population as a whole (Brickley \& Agarwal, 2003; Wood et al., 1992). There is also the concern that less people reached old age in the past, although Jackes (2000) has shown that this concern is more a product of high infant mortality and that human longevity has remained largely unchanged.

A number of challenges remain in bioarchaeological studies of bone loss. We suggest that one of the main reasons for the conflicting patterns in bone loss may be methodological. One critical problem is 
that researchers have used different research protocols, with not just different assessments of bone loss (e.g., bone mass, mineral density, microstructure, remodeling) but also the sampling of bone tissue across different skeletal regions of the body that make comparison between studies difficult. This is because age-related changes in bone quantity and quality are not the same, and do not occur uniformly across the skeleton, as skeletal tissues are differentially affected by mechanical loading environments and hormonal and metabolic histories (Agarwal, 2012, 2016; Agarwal \& Beauchesne, 2011 ; Brickley \& Ives, 2008; Cho \& Stout, 2011; Gosman, Stout, \& Larsen, 2011; Peck \& Stout, 2007). Further, cortical and trabecular bone also respond to hormonal and metabolic demands differently (Compston, 1999; Gosman et al., 2011). Observing a snapshot of bone maintenance at one scale will give a skewed perspective on the complex and unique path that has created the observed bone morphology of the whole skeleton. If we account for the heterogeneity of bone in our methods, we could be more certain that our interpretations reflect differences or similarities that arise from biocultural and lived experiences.

The goal of this study was to examine and compare patterns of age- and sex-related bone loss in a variety of skeletal tissue sites within the same skeletal sample. Specifically, based on findings in recent bioarchaeological studies (Agarwal et al., 2004; Agarwal \& Stout, 2003; Brickley \& Ives, 2008; Ives et al., 2017; Mays, Turner-Walker, \& Syversen, 2006; Robling \& Stout, 2000), we hypothesize that bone mass and maintenance in trabecular bone sites versus cortical bone sites will show differing patterns of age-related bone loss, with cortical bone sites showing greater sex difference in bone loss, similar to contemporary Western populations, and trabecular bone showing loss at earlier ages. A multi-method approach can reveal differential timing of bone loss between skeletal elements, and detailed considerations of biocultural context can then help explain the timing of these bone loss events.

\section{2 | MATERIALS}

Skeletal samples were taken from archaeological skeletons excavated from the site of Velia. Velia is located on the west coast of Italy, in the Campania region (see Figure 1). The city has a very long occupation history (Greco, 1975; Morel, 1999), but is primarily known for its role during the Roman period. Velia was appreciated among the Roman ruling classes as a spa retreat and center of learning but it was more widely acknowledged as an important trading center and port in southern Italy (Crowe et al., 2010; Marzano, 2007). The skeletal material used in this research dates to the Imperial Period, or the 1st and 2nd centuries AD (Crowe et al., 2010). Subsistence practices for this population were largely typical of other contemporary Italian Roman sites (see Craig et al., 2009 for a detailed review, including isotopic analyses). Briefly, their diet was largely cereal based, with the additional consumption of olives, wine, and animal protein (from both marine and terrestrial sources) (Craig et al., 2009). There were minor sex differences in the diet, with males consuming slightly more animal protein than females on average (Craig et al., 2009). Data from Crowe et al. (2010)

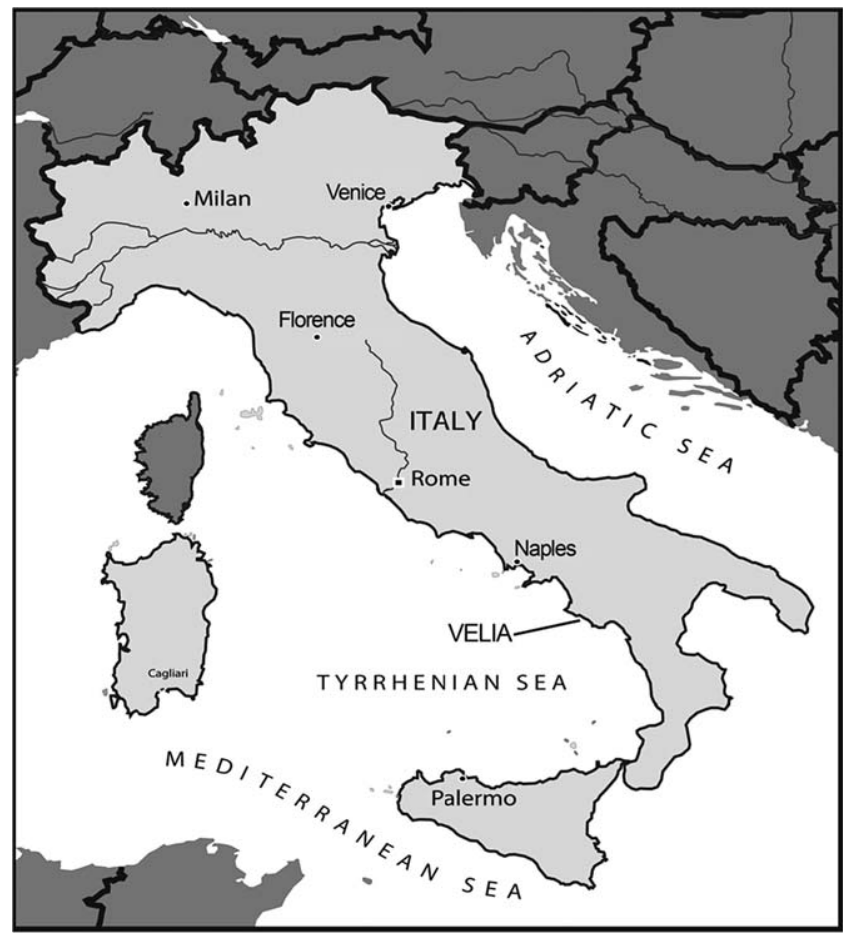

FIGURE 1 Map showing the location of Velia along the Tyrrhenian coast, Italy

suggest that this sex difference was largely caused by a sub-group of males who are hypothesized to have a unique occupation as fishermen (also identified by the presence of external auditory exostoses) that differed from other males and females at the site. Fishing and fishingrelated commerce were known to have been part of daily life (Craig et al., 2009; Crowe et al., 2010; Marzano, 2007). The people of Velia represented in this research were most likely from the lower classes of Roman society (Fiammenghi, 2003), and the archaeological context suggests they were part of a tight-knit, culturally similar community (Bondioli, personal communication, 2011). Craig et al. (2009, p. 574) note that literary sources, notably the famous geographer Strabo, refer to Velia as a well governed city, and one that made good use of the maritime resources available to it. At the same time, subsistence off of the land was still important. Local agriculture formed an important part of daily life, like most urban centers at the time (Greco \& Schnapp, 1986). In addition, nearly 80 hectares of arable land within the city boundaries was devoted to agriculture on a permanent basis (Greco, 1999). Subsistence practices at Velia depended heavily on the river valleys surrounding the site (Bencivenga, 1990; Schmeidt, 1970). Historians note that Velia likely had the foremost port facilities of any city south of Naples at its peak in the Imperial period (Greco, 1975; Morel, 1999).

There are a number of advantages to using skeletal material from the archaeological population of Velia. Sex and age distributions are fairly well balanced, albeit with a small bias toward males overall. Further, the mortality profile for the Velia population (Beauchesne \& Agarwal, 2014) shows that differential preservation or excavation was not a large biasing factor, given that many young infants were 
TABLE 1 Sample distribution of the Velia skeletal population by age-at-death and sex.

\begin{tabular}{|c|c|c|c|}
\hline Age group & Females & Male & Total \\
\hline \multicolumn{4}{|c|}{ Radiogrammetry of the second metacarpal } \\
\hline $18-29$ years & 7 & 6 & 13 \\
\hline $30-49$ years & 15 & 20 & 35 \\
\hline $50+$ years & 10 & 13 & 23 \\
\hline Total & 32 & 39 & 71 \\
\hline \multicolumn{4}{|c|}{ Rib cross-sectional area measures } \\
\hline $18-29$ years & 10 & 5 & 15 \\
\hline $30-49$ years & 11 & 22 & 33 \\
\hline $50+$ years & 9 & 13 & 22 \\
\hline Total & 30 & 40 & 70 \\
\hline \multicolumn{4}{|c|}{ Rib histomorphometry } \\
\hline $18-29$ years & 7 & 2 & 9 \\
\hline $30-49$ years & 9 & 13 & 22 \\
\hline $50+$ years & 10 & 11 & 21 \\
\hline Total & 26 & 26 & 52 \\
\hline \multicolumn{4}{|c|}{ Computed tomography of trabecular architecture ( $\mathrm{L} 4$ vertebrae) } \\
\hline $18-29$ years & 6 & 4 & 10 \\
\hline $30-49$ years & 7 & 14 & 21 \\
\hline $50+$ years & 6 & 10 & 16 \\
\hline Total & 19 & 28 & 47 \\
\hline
\end{tabular}

recovered and that the mortality profile as a whole follows the typical pattern of high mortality in the youngest and oldest age groups as expected in historical populations (Chamberlain, 2000).

The number and distribution of individuals used for each method in this study are summarized in Table 1 . The adult skeletal sample at Velia consists of 115 skeletons, and 88 of those 115 adult skeletons (76.5\%) were used in this research. For the radiogrammetry measure, a total of 71 adult individuals were analyzed $(M=39, F=32)$. For the measures of the rib, a total of 70 adult individuals were used $(M=40$; $F=30$ ) for assessments of cross-sectional area. Sample size was smaller for histomorphometric analyses $(M=26 ; F=26)$, due to the effects of microstructural diagenesis. Finally, a sample of 47 individuals ( $M=28 ; F=19$ ) was used for the computed tomography of trabecular architecture. We used broad, conservative age groups (18-29 years; 30-49 years; 50 + years) as the assignment of precise age estimations of adult skeletons is highly problematic (Jackes, 2000), particularly in the case of older adults. These particular cut-off points were also chosen because they reflect important transitional stages in the human life cycle. Specifically, the estimated 18-29 age category captures event of the adolescent year and the development of peak bone mass. The "middle" age category (30-49) reflects the pre-menopausal period in females. Finally, the older age category $(50+)$ reflects the period of accelerated loss of bone mass with aging driven by the loss of sex steroids in both sexes (Riggs et al., 2008). Age estimation in adults was assessed using multiple indicators including degenerative changes on the pubic symphysis (Brooks \& Suchey, 1990), auricular surface changes (Lovejoy, Meindl, Pryzbeck, \& Mensforth, 1985), morphological changes in the sternal end of ribs (Isşcan, Loth, \& Wright, 1984;
İscan, Loth, \& Wright, 1985), and dental wear (Lovejoy, 1985). Individuals that could not be reliably placed within one of the three age groups (indeterminate adult) due to preservation issues were not used.

Sex determination was carried out using standard sex determination methods, with emphasis on pelvic (pubic bone) morphological traits including the ventral arc, sub-pubic angle, sub-pubic concavity, and the sciatic notch (Acsàdi \& Nemeskèri, 1970; Brothwell, 1981; Buikstra \& Ubelaker, 1994). Sex-related features of the skull (Buikstra \& Ubelaker, 1994) were also examined in order to increase accuracy (Mays, 1998). Adult individuals with indeterminate sex due to preservation were not utilized.

\section{3 | METHODS}

The present study applies considerations of skeletal variability (Peck \& Stout, 2007) and remodeling histories among the different bone envelopes (Gosman et al., 2011) in a particular archaeological population, and is interpreted through biocultural and life course perspectives. Specifically, the aim of this research was to apply multiple methods of investigating bone loss in an archaeological population, so that a life course approach could be implemented to explore how bone maintenance and loss occurred over the life cycle. What facilitates the development of a life course approach is not only the use of multiple methods, but the fact that the methods reflect different types of bone and regions over the skeleton with different bio-historical trajectories. Specifically, changes in trabecular architecture are interpreted as representing more short-term changes in bone, given the high metabolic activity and great sensitivity to biomechanical strain (Barak, Lieberman, \& Hublin, 2011; Gosman et al., 2011). Remodeling in the ribs is interpreted at the "mid-range level," as intra-cortical remodeling is slower than in cancellous bone (Compston, 1999), but can react more quickly at the tissue level than larger morphological changes at the wholebone level (Epker \& Frost, 1964). Finally, radiogrammetry of the second metacarpal and cross-sectional area measures of the ribs are seen as representing longer-term changes in cortical bone, as whole-bone morphology is a product of years of interplay between dietary, hormonal, biomechanical, and lifestyle factors (Gosman et al., 2011; Martin \& Burr, 1989; Ruff et al., 2006).

\section{1 | Vertebral trabecular architecture}

There have been a few studies of vertebral trabecular architecture in archaeological bone (Agarwal et al., 2004; Chirchir et al., 2015; Gosman et al., 2011; Kneissel et al., 1997; Ryan \& Shaw, 2015) and this methodology has been shown to be a sensitive marker of remodeling activity. This study examined trabecular architecture in the fourth lumbar vertebrae (L4), as it has been the most extensively studied clinically and bioarchaeologically (Agarwal et al., 2004; Kneissel et al., 1997), and is more sensitive to structural changes during growth and development (Roschger et al., 2001). This study examined standardized measures of trabecular architecture, including bone volume (BV/TV), degree of anisotropy (DA), trabecular thickness (Tb.Th), trabecular separation (Tb.SP), trabecular number (Tb.N), connective density (Conn.D), and the 
structural model index (SMI) (Parfitt et al., 1987). BV/TV is an assessment of the amount of trabecular bone present within a sample area. Conn.D is an assessment of how well connected individual trabeculae are connected to each other (Parfitt et al., 1987). DA examines the changing direction of trabeculae with age (Njeh, Cheng, Elliot, \& Meunier, 1999). As vertebral trabecular bone ages the organization of individual trabeculae shift from a more isotropic state (equal strength in all directions) to more anisotropic one (Snyder, Piazza, Edwards, \& Hayes, 1993). SMI measure showed that while trabeculae did shift from a more plate-like to rod-like model of bone.

L4 vertebrae were scanned using an HR-pQCT machine (XtremeCT, Scanco Medical AG, Brüttisellen, Switzerland). Using medical tape, vertebrae were placed on a carbon fiber cast that was later fixed within the gantry of the scanner. Medical foam was used to sup port the anterior region of the vertebrae to make sure their orientation was kept horizontal and not tilted in either the anterior-posterior or medial-lateral directions. The scanning region of interest was standardized in the scanner's "scout-view" by taking the anterior-posterior distance of vertebrae, dividing by 2 , and selecting $4.5 \mathrm{~mm}$ on either side of the midline of the bone. In this way the central $9 \mathrm{~mm}$ of trabecular bone could be examined for each vertebra. From this standardized location, the scanner captured 1,000 projections, which were acquired over 180 degrees with a 200-ms integration time at each angular position. Total scan time was 6 min for a total of 220 2D slices. The field of view (12.6 cm; $3072 \times 3072$ matrix) was reconstructed using a modified Feldkamp algorithm, for a nominal voxel thickness of $41 \mu \mathrm{m}$.

Image analysis was performed on an OpenVMS Alpha-based workstation (HP DS25; Hewlett Packard Corporation, Palo Alto, CA) using Image Processing Language software provided by the scanner manufacturer (IPL v5.08b, Scanco Medical AG). For each vertebra, the cortical shell was manually segmented away from the underlying trabecular bone by tracing the endocortical margin of the cortical shell for every 20 slices of the 220 slices obtained per vertebra. A fixed mineralization threshold to segment bone from marrow was not used, as the range of tissue densities present in the sample varied too greatly, which is not unexpected in archaeological samples. Instead, an automatic histogram based algorithm that determines an "optimal" threshold on a sampleby-sample basis (Ridler, 1978), as well as a light Gaussian filter ( $\sigma=0.5$, kernel $=3$ ) to remove high frequency noise was used. Simple voxel counting was used to determine bone volume fraction (BV/TV). Measures of trabecular number (Tb.N), spacing (Tb.Sp), and thickness (Tb.Th) were assessed directly using a model independent sphere filling method outlined by Hildebrand and Ruegsegger (1997). The DA was determined by the ratio of major and minor principal components of the MIL ellipsoid (Harrigan \& Mann, 1984). The SMI was calculated from a triangular surface representation of 3D binary data (Hildebrand \& Ruegsegger, 1997). Finally Conn.D was assessed using the Euler number (Odgaard \& Gundersen, 1993).

\section{2 | Rib-Cortical bone histomorphometry}

Remodeling in human ribs has been well studied in anthropology (Cho \& Stout, 2003; Mulhern, 2000; Robling \& Stout, 2000; Schultz, 2001;
Stout \& Lueck, 1995; Stout \& Teitelbaum, 1976). Ribs are used in histomorphometric studies of archaeological populations as they are easily accessible for invasive sampling and are typically well preserved. Most importantly, rib tissue is less biomechanically influenced as compared to other skeletal areas commonly used in histomorphometric analyses, such as the femur (Robling \& Stout, 2003), but is metabolically active enough that earlier signs of bone loss would be detected there.

Rib thin sections were prepared by removing small $1 \mathrm{~cm}$ sections of bone from the mid-shaft region of a mid-thoracic rib (between ribs \#5-8) using an Isomet ${ }^{\circledR}$ slow-speed saw. Surface dirt was removed with gentle washing and then the small bone samples were dehydrated using an ascending ethyl alcohol series to remove excess moisture and to facilitate complete infiltration of the epoxy resin and left for $24 \mathrm{hr}$ to air-dry completely. The $1 \mathrm{~cm}$ rib samples were embedded using Buehler's Epo-Thin ${ }^{\circledR}$ resin, following the manufacturer's protocols. The embedded blocks were mounted on to an Isomet ${ }^{\circledR}$ slow-speed saw and thinner transverse sections of approximately $2 \mathrm{~mm}$ were cut from the larger block. The $2 \mathrm{~mm}$ sections were then mounted to glass slides using 2 Ton ${ }^{\circledR}$ Clear Epoxy (Devcon) and the slides were left to cure for $24 \mathrm{hr}$ before final preparation. The final steps involved grinding the mounted sections down to a thickness of 50-100 microns using a Buehler PetroThin ${ }^{\circledR}$ grinding system. Prior to the final mounting of cover slips, each slide was cleaned by a five-to-ten second immersion in Xylene to improve visual clarity. Immediately after, while the slides were still wet from Xylene immersion, a few (2-3) drops of Permount $\mathbb{R}$ mounting medium were then placed over the thin section and then cover-slipped to protect the specimens. Microscopic analysis was conducted using a Leica DM 2500 upright microscope and Qlmaging Micropublisher 5.0 RTV digital camera, using both polarized and plane light. Specimens with microstructures that were significantly obscured by taphonomic changes were discarded from the analysis $(N=18$, out of the original 70).

The Bioquant ${ }^{\circledR}$ image analysis software was used to measure histomorphometric variables. Histomorphometric methodology followed established protocols (Mulhern, 2000; Robling \& Stout, 2000; Stout \& Paine, 1994). Sampled cortical area, osteons, Haversian canals, and osteon fragments were manually traced. For whole osteons and their fragments (to assist counting), a line was drawn along a given reversal (cement) line. Haversian canals were measured by tracing along the outer edge of the canal, where it meets osteonal bone. The histomorphometric measures discussed in this article are mean osteon size (On.Ar), osteon population density (OPD), mean annual activation frequency (Ac.F), and mean annual bone formation rate (BFR).

OPD is determined by adding all complete and fragmentary osteons for all fields, divided by the total area examined (Cho \& Stout, 2003; Wu, Schubeck, Frost, \& Villanueva, 1970). This provides a measure in $\# / \mathrm{mm}^{2}$. This is the standard method for assessing OPD (Cho \& Stout, 2003; Frost, 1987a, 1987b; Robling \& Stout, 2000; Stout \& Lueck, 1995; Stout \& Paine, 1994; Wu et al., 1970), although this method uses direct measurement of cortical area rather than estimates based on a Merz reticule (Robling \& Stout, 2000). 
The mean activation frequency, or Ac.F is the mean number of osteons created annually, per $\mathrm{mm}^{2}$ of bone (Stout \& Paine, 1994; Wu et al., 1970). Ac.F is calculated as follows:

$$
\text { Ac.F }=\text { AOC } /(\text { chronological age }-12.5 \text { years })
$$

Accumulated osteon creation (AOC) is the sum of complete, fragmentary, and missing osteons (described below) for any given OPD (Stout \& Paine, 1994). One must account for (estimate) missing osteons because bone constantly remodels and will eventually produce an asymptote in OPD where secondary osteonal bone occupies the entire cortex (Frost, 1987a, 1987b; Stout \& Paine, 1994). Remodeling after the asymptote is reached will remove evidence of previous osteons, and thus a true determination of AOC must take into account these missing osteons. The "effective birth" of adult compacta (cortical bone) does not equal chronological age because modeling drifts during growth remove bone that was previously present, and thus true "adult" bone is always younger than a person's chronological age (Wu et al., 1970). Wu et al. (1970) determined that the effective birth of adult compacta in the human 6th rib occurs around 12.5 years of age. This is the age when most of the adult compacta has formed and will not be removed by further modeling. When calculating Ac.F it is therefore necessary to subtract 12.5 from the chronological age (determined from estimates based on osteological aging techniques). Individuals in this study are placed into three broad age groups (18-29; 30-49; 50+), and the median of each group is used as chronological age, as recommended by Stout and Lueck (1995) and Cho and Stout (2003). For example, in the 18-29 age group, the age of 24 is used as chronological age. For individuals in the $50+$ group, age 50 is used as chronological age. $A O C$ is defined as: $A O C=\beta \times O P D$. The equation for $\beta$ is taken from Frost (1987a). Finally, BFR is an estimation of true bone formation rate (Parfitt et al., 1983). It averages the frequency of osteon creations over mean osteon size, thus approximating the rate of bone formed in a year. Frost (1987a,b) developed the equation based on Wu et al.'s (1970) seminal research. Wu et al. (1970) did not account for missing osteons, and thus Frost (1987a) introduced the algorithm $\beta$ to account for the missing osteons. Following Stout and Lueck (1995), the equation used for BFR was:

$$
\mathrm{BFR}=\mathrm{Ac} . \mathrm{F} \cdot \text { Mean Osteon Area }
$$

\section{3 | Rib-Cross-sectional area}

In addition to histomorphometric measures, the total area (Tt.Ar), medullary area (Md.Ar.), and cortical area (Ct.Ar) of rib cross-sections were also measured. Thin section slides were placed under a Leica MZ6 dissecting scope with a QImaging Micropublisher 5.0 RTV digital camera. The outer area (along periosteal border) was traced and the Bioquant ${ }^{\circledR}$ software then determined the Tt.Ar for the rib specimen. Md.Ar was determined the same way, but traced along the margin where rib trabeculae joined the cortical space (medullary margin). Ct.Ar was determined afterwards manually by subtracting medullary area from total area. Finally, relative or percent Ct.Ar was determined by dividing Ct.Ar by Tt.Ar, and then multiplying by 100 (Ct.Ar/Tt.Ar $\times 100$ ) (Cho \& Stout, 2003).

\subsection{Second metacarpal-Radiogrammetry}

Metacarpal radiogrammetry has a long history in biomedical research (Barnett \& Nordin, 1960), and is a well-established method to track bone growth and development, as well as sex- and age-related patterns of aging (Garn, 1970; Ives \& Brickley, 2005; Virtama \& Helelä, 1969). While radiogrammetry is no longer a common diagnostic method among clinicians with the rise of densitometric measures of BMD as the primary measure of bone loss in living subjects, a number of researchers have pointed out its advantages (Boonen et al., 2005; Dey et al., 2000; Montalbán, Rico, Cortés, \& Pedrera Zamorano, 2001; Nielsen, 2001; Reed, Murray, Abdy, Francis, \& McCaskie, 2004; Rosholm, Hyldstrup, Backsgaard, Grunkin, \& Thodberg, 2001). There is substantial support for the fact that radiogrammetry is a sensitive marker to changes in bone quantity (Nielsen, 2001).

The methodological value of metacarpal radiogrammetry has been recognized in bioarchaeology, and the method has been particularly informative about sex- and age-related patterns of bone growth and loss in the past (Beauchesne \& Agarwal, 2014; Glencross \& Agarwal, 2011; Gosman et al., 2011; Ives \& Brickley, 2004; Lazenby, 2002; Mays, 1996, 2000, 2001, 2006). Radiogrammetry is a rapid and nondestructive method, and a good proxy for overall bone mineral desnity (Ives \& Brickley, 2005; Mays, 2006). In addition, radiogrammetry is particularly well suited to inter-group comparisons (Haara et al., 2006), making it ideal for bioarchaeology. The measurements protocols for this study follow guidelines from Ives and Brickley (2004) and are also described in detail by Beauchesne and Agarwal (2014). Total length (L), total width (TW), and medullary width (MW) were taken directly off of $X$-ray film. The cortical thickness (CT) measurement was determined by subtracting MW from TW. Finally, the cortical index measure $(\mathrm{Cl})$ was established by the following formula: CT/TW and multiplied by 100 to reflect a percentage of cortical bone present.

\section{5 | Statistical analyses}

Statistical analyses for all methods were conducted using the 0.05 significance level with the JMP 9 statistical software package (SAS Insititute Inc.). All measures were tested for normality. Measures that failed normality tests were assessed through non-parametric analyses and are discussed within each results section.

\section{4 | RESULTS}

\section{1 | Vertebral trabecular architecture}

Age differences were first explored for each sex separately using oneway ANOVA and Tukey's HSD post-hoc test, as well as the KruskalWallis test when normality assumptions failed (see Table 2). Female bone volume (BV/TV) differed between the young and middle age group, but did not show a difference with the older age group. None of the age changes for BV/TV in females were statistically significant. 
TABLE 2 Age-related differences in vertebral trabecular architecture

\begin{tabular}{|c|c|c|c|c|c|c|c|c|c|c|c|c|c|c|}
\hline \multirow[b]{2}{*}{ Age group } & \multicolumn{2}{|c|}{ BV/TV } & \multicolumn{2}{|c|}{ Tb.N (1/mm) } & \multicolumn{2}{|c|}{ Tb.Sp (mm) } & \multicolumn{2}{|c|}{ Tb.Th (mm) } & \multicolumn{2}{|c|}{ Conn.D $\left(\mathrm{mm}^{-3}\right)$} & \multicolumn{2}{|l|}{ SMI } & \multicolumn{2}{|l|}{ DA } \\
\hline & Mean & SD & Mean & SD & Mean & SD & Mean & SD & Mean & SD & Mean & SD & Mean & SD \\
\hline \multicolumn{15}{|l|}{ Females } \\
\hline $18-29$ years, $N=6$ & 0.37 & 0.10 & 1.31 & 0.18 & 0.72 & 0.14 & 0.33 & 0.094 & 3.38 & 1.17 & -0.17 & 1.18 & 1.26 & 0.09 \\
\hline $30-49$ years, $N=7$ & 0.28 & 0.12 & 1.20 & 0.17 & 0.80 & 0.12 & 0.26 & 0.053 & 3.05 & 0.66 & 0.61 & 1.61 & 1.35 & 0.07 \\
\hline $50+$ years, $N=6$ & 0.28 & 0.15 & 1.03 & 0.15 & 0.96 & 0.14 & 0.35 & 0.15 & 2.07 & 0.44 & 0.77 & 1.51 & 1.34 & 0.01 \\
\hline ANOVA & \multicolumn{2}{|l|}{ N.S } & \multicolumn{2}{|c|}{$18-29$ vs. $50+$} & \multicolumn{2}{|c|}{$18-29$ vs. $50+$} & \multicolumn{2}{|l|}{$\mathrm{N} / \mathrm{A}$} & \multicolumn{2}{|l|}{$\mathrm{N} / \mathrm{A}$} & \multicolumn{2}{|l|}{ N.S } & \multicolumn{2}{|l|}{ N.S } \\
\hline Kruskal-Wallis & & & & & & & N.S & & $*$ & & & & & \\
\hline \multicolumn{15}{|l|}{ Males } \\
\hline $18-29$ years, $N=4$ & 0.35 & 0.03 & 1.40 & 0.15 & 0.66 & 0.08 & 0.25 & 0.003 & 5.31 & 1.01 & -0.03 & 0.37 & 1.22 & 0.02 \\
\hline $30-49$ years, $N=14$ & 0.34 & 0.10 & 1.25 & 0.16 & 0.76 & 0.10 & 0.32 & 0.095 & 3.13 & 0.78 & 0.18 & 1.13 & 1.28 & 0.08 \\
\hline $50+$ years, $N=10$ & 0.32 & 0.11 & 1.18 & 0.15 & 0.84 & 0.12 & 0.33 & 0.09 & 2.73 & 0.78 & 0.46 & 1.08 & 1.31 & 0.08 \\
\hline ANOVA & N/A & & $18-29$ & $50+$ & $18-29 \mathrm{vs}$ & $50+$ & $N / A$ & & $\begin{array}{l}18-29 \\
18-29\end{array}$ & $\begin{array}{l}50+ \\
30-49\end{array}$ & N.S & & N.S & \\
\hline Kruskal-Wallis & N.S & & & & & & N.S & & & & & & & \\
\hline
\end{tabular}

BV/TV, bone volume; Tb.N, trabecular number; Tb.Sp, trabecular spacing; Tb.Th, trabecular thickness; Conn.D, connective density; SMI, structural model index; DA, Anisotropy-Direction/Orientation of trabeculae.

Significance measured at the 0.05 level. Statistically significant sex differences were only found in the Conn.D measure, where mean values of were consistently greater in males and were significantly different for young and old age adults.

*Indicates a significant difference with age using Kruskal-Wallis tests.

Male BV/TV was slightly different between the middle and old age groups but again, not statistically significant. For the trabecular number measure (Tb.N), female means declined steadily with age and were significantly different between the young and older age groups. Similarly, male Tb.N declined with age and was also statistically significantly different between the young and older age categories. Trabecular spacing (Tb.Sp) in females increased with age, and was significantly different between the young and older groups. The same pattern was seen in males for Tb.Sp, with spacing increasing with age and a significant difference observed between the youngest and oldest age groups. Trabecular thickness (Tb.Th) in females decreased from young to middle age, but then rose again into old age. Changes to Tb.Th in females with age were not significant however. Male Tb.Th increased steadily with age, but did not reach statistical significance. Conn.D decreased with age in females in a statistically significant way, but because normality could not be assumed, the non-parametric Kruskal-Wallis test was used and post-hoc tests were not available. In males, Conn.D also declines with age, and statistically significant differences were noted between the young age group and the middle and old age categories. The SMI of trabecular bone, a way to three-dimensionally describe trabeculae as either plate- or rod-like, increased with age in females, but this difference was not statistically significant. A similar pattern was observed in males, with SMI increasing with age but not significantly. The final measure, DA, increased with age in both sexes and also did not reach statistical significance.

Sex differences were also explored for the trabecular architecture measures using Student's $t$-tests for each age group. None of the mean measures for any parameters were statistically significantly different between the male and female age groups, thus indicating a fairly close relationship between male and female trabecular bone maintenance and loss. Only the Conn.D measure showed a significant sex difference. Mean values of Conn.D were consistently greater in males and were significantly different for young and old age adults.

\section{2 | Rib-Histomorphometry}

The measures that are explored in detail here are On.Ar (mean osteon area), OPD, Ac.F (mean annual activation frequency), and BFR (mean annual bone formation rate) (see Table 3). These composite measures reflect important changes in remodeling over the life course. Age differences were first explored using one-way ANOVA and Tukey's HSD post-hoc test, as well as the Kruskal-Wallis test when normality assumptions failed. OPD increased significantly in females with age, with the significant difference occurring between the young and older age categories. While male OPD also increased with age, it did not do so in a statistically significant way, although statistical significance was nearly reached $(p=.08)$. Ac.F showed an apparent decrease with age in females and was significantly different across all age groups. The same pattern was noted for males, where Ac.F differed with age and was significantly different across all ages. In both sexes, BFR decreased with age and was significantly different between all age groups. Sex differences for each histomorphometric measure were explored using Student's $t$-tests for each age group. For each measure of cortical microstructure, male and female values were extremely close and no significant sex differences were noted for any of the variables.

\section{3 | Rib-Cross-section area}

Age differences were first explored using one-way ANOVA and Tukey's HSD post-hoc test, as well as the Kruskal-Wallis test when normality assumptions failed (see Table 4). Total area (Tt.Ar) varied in 
TABLE 3 Age-related differences in cortical histomorphometry

\begin{tabular}{|c|c|c|c|c|c|c|c|c|}
\hline \multirow[b]{2}{*}{ Age group } & \multicolumn{2}{|c|}{ On.Ar $\left(\mu^{2}\right)$} & \multicolumn{2}{|c|}{ OPD (\#/mm²) } & \multicolumn{2}{|c|}{ AC.F (\#/mm²/year) } & \multicolumn{2}{|c|}{ BFR $\left(\mathrm{mm}^{2} / \mathrm{mm}^{2} /\right.$ year $)$} \\
\hline & Mean & SD & Mean & SD & Mean & SD & Mean & SD \\
\hline \multicolumn{9}{|l|}{ Females } \\
\hline $18-29$ years, $N=7$ & 31 & 5 & 11.57 & 2.47 & 1.69 & 0.008 & 0.052 & 0.008 \\
\hline $30-49$ years, $N=9$ & 30 & 5 & 14.17 & 2.33 & 0.83 & 0.32 & 0.026 & 0.014 \\
\hline $50+$ years, $N=10$ & 27 & 4 & 14.93 & 2.74 & 0.52 & 0.005 & 0.014 & 0.002 \\
\hline \multirow[t]{3}{*}{ ANOVA } & \multirow[t]{3}{*}{ N.S } & & \multirow{3}{*}{\multicolumn{2}{|c|}{$18-29$ vs. $50+$}} & \multirow{3}{*}{\multicolumn{2}{|c|}{$\begin{array}{l}18-29 \text { vs. } 50+ \\
18-29 \text { vs. } 30-49 \\
30-49 \text { vs. } 50+\end{array}$}} & \multirow{3}{*}{\multicolumn{2}{|c|}{$\begin{array}{l}18-29 \text { vs. } 50+ \\
18-29 \text { vs. } 30-49 \\
30-49 \text { vs. } 50+\end{array}$}} \\
\hline & & & & & & & & \\
\hline & & & & & & & & \\
\hline \multicolumn{9}{|l|}{ Males } \\
\hline $18-29$ years, $N=2$ & 29 & 2 & 9.10 & 2.33 & 1.68 & 0.007 & 0.049 & 0.004 \\
\hline $30-49$ years, $N=13$ & 30 & 3 & 14.39 & 2.51 & 0.73 & 0.01 & 0.021 & 0.003 \\
\hline $50+$ years, $N=11$ & 28 & 7 & 14.90 & 4.01 & 0.52 & 0.007 & 0.015 & 0.004 \\
\hline \multirow[t]{3}{*}{ ANOVA } & \multirow[t]{3}{*}{ N.S } & & \multirow{3}{*}{\multicolumn{2}{|c|}{ N.S }} & \multirow{3}{*}{\multicolumn{2}{|c|}{$\mathrm{N} / \mathrm{A}$}} & \multirow{3}{*}{\multicolumn{2}{|c|}{$\begin{array}{l}18-29 \text { vs. } 50+ \\
18-29 \text { vs. } 30-49 \\
30-49 \text { vs. } 50+\end{array}$}} \\
\hline & & & & & & & & \\
\hline & & & & & & & & \\
\hline
\end{tabular}

On.Ar, mean osteon area; OPD, osteon population density; AC.F, mean annual activation frequency; BFR, mean annual bone formation rate. Significance measured at the 0.05 level. No sex statistically significant differences were found at any age group for cortical histomorphometry.

*Indicates a significant difference with age using Kruskal-Wallis tests.

females with age, with a decrease from young to middle age, and then increasing into old age, but none of these changes were statistically significant. Total area showed an apparent but non-significant decrease in males, but this decline is probably the result of sampling error and the cross-sectional nature of the study, and given that total area does not typically decline in longitudinal studies (Takahashi \& Frost, 1966). However, a recent study (Seeman, 2007) highlighted that periosteal resorption was possible, and so the decline in total area in males between middle and old age might reflect a real, but minor decline. Medullary area (Md.Ar) increased with age in females and males, but these differences were not statistically significant for either sex. Ct.Ar decreased with age in both females and males, and was statistically significant between the young and old age categories for both sexes. Percent cortical area (Ct.Ar/Tt.Ar $\times 100)$ decreased significantly with age in females and males, with significant differences occurring between young and old age group.

Student's $t$-tests were used for each age group to explore sex differences for the cross-sectional area changes in ribs. Mean values for Tt.Ar, Ct.Ar, and Md.Ar were consistently larger in males and a statistically significant sex difference was found for each age group and

TABLE 4 Age-related differences in rib cross-sectional area measures

\begin{tabular}{|c|c|c|c|c|c|c|c|c|}
\hline \multirow[b]{2}{*}{ Age group } & \multicolumn{2}{|c|}{ Tt.Ar $\left(\mathrm{mm}^{2}\right)$} & \multicolumn{2}{|c|}{ Ct.Ar $\left(\mathrm{mm}^{2}\right)$} & \multicolumn{2}{|c|}{$\operatorname{Md} . \operatorname{Ar}\left(\mathrm{mm}^{2}\right)$} & \multicolumn{2}{|c|}{ Ct.Ar/Tt.Ar (\%) } \\
\hline & Mean & SD & Mean & SD & Mean & SD & Mean & SD \\
\hline \multicolumn{9}{|l|}{ Females } \\
\hline $18-29$ years, $N=10$ & 55.27 & 16.21 & 23.39 & 4.51 & 31.89 & 13.15 & 43.96 & 7.95 \\
\hline $30-49$ years, $N=11$ & 53.92 & 10.78 & 19.70 & 4.98 & 34.22 & 10.29 & 37.48 & 11.16 \\
\hline $50+$ years, $N=9$ & 58.71 & 8.82 & 16.88 & 3.98 & 41.83 & 8.51 & 29.08 & 6.39 \\
\hline ANOVA & \multicolumn{2}{|l|}{ N.S } & \multicolumn{2}{|c|}{$18-29$ vs. $50+$} & \multicolumn{2}{|l|}{ N.S } & \multicolumn{2}{|c|}{$18-29$ vs. $50+$} \\
\hline \multicolumn{9}{|l|}{ Males } \\
\hline $18-29$ years, $N=5$ & 86.24 & 9.72 & 34.09 & 7.43 & 52.15 & 8.97 & 39.53 & 7.68 \\
\hline $30-49$ years, $N=22$ & 80.67 & 17.09 & 26.16 & 6.70 & 54.52 & 12.16 & 32.30 & 4.83 \\
\hline $50+$ years, $N=13$ & 77.20 & 13.75 & 23.56 & 5.14 & 53.64 & 11.71 & 30.79 & 6.16 \\
\hline ANOVA & \multicolumn{2}{|l|}{ N.S } & \multicolumn{2}{|c|}{$\begin{array}{l}18-29 \text { vs. } 50+, \\
18-29 \text { vs. } 30-49\end{array}$} & \multicolumn{2}{|l|}{ N.S } & \multicolumn{2}{|l|}{$\mathrm{N} / \mathrm{A}$} \\
\hline Kruskal-Wallis & & & & & & & $*$ & \\
\hline
\end{tabular}

Tt.Ar, total area; Ct.Ar, cortical area; Md.Ar, medullary area; Ct.Ar/Tr.Ar, percent cortical area.

Values for $\mathrm{Tr}$.Ar, Ct.Ar, and En.Ar in $\mathrm{mm}^{2}$. Ct.Ar/Tt.Ar reported as a percentage. Significance measured at the 0.05 level.

*Indicates a significant difference with age using Kruskal-Wallis tests. Mean values for total area, cortical area, and endosteal area were consistently larger in males and a statistically significant sex difference was found for each age group and variable. No significant sex differences were noted for percent cortical area in any age group. 
TABLE 5 Age-related differences in metacarpal cortical bone

\begin{tabular}{|c|c|c|c|c|c|c|c|c|}
\hline \multirow[b]{2}{*}{ Age group } & \multicolumn{2}{|l|}{ TW } & \multicolumn{2}{|l|}{ MW } & \multicolumn{2}{|l|}{ CT } & \multicolumn{2}{|l|}{$\mathrm{Cl}$} \\
\hline & Mean & SD & Mean & SD & Mean & SD & Mean & SD \\
\hline \multicolumn{9}{|l|}{ Females } \\
\hline $18-29$ years, $N=7$ & 7.52 & 0.38 & 3.39 & 0.67 & 4.13 & 0.48 & 55.11 & 7.52 \\
\hline $30-49$ years, $N=15$ & 8.17 & 0.63 & 4.13 & 0.99 & 4.04 & 0.77 & 49.73 & 10.02 \\
\hline $50+$ years, $N=10$ & 8.17 & 0.69 & 5.05 & 0.81 & 3.12 & 0.40 & 38.44 & 6.02 \\
\hline \multirow[t]{2}{*}{ ANOVA } & \multirow{2}{*}{\multicolumn{2}{|c|}{ N.S }} & \multirow{2}{*}{\multicolumn{2}{|c|}{$\begin{array}{l}18-29 \text { vs. } 50+ \\
30-49 \text { vs. } 50+\end{array}$}} & \multirow{2}{*}{\multicolumn{2}{|c|}{$\begin{array}{l}18-29 \text { vs. } 50+ \\
30-49 \text { vs. } 50+\end{array}$}} & \multirow{2}{*}{\multicolumn{2}{|c|}{$\begin{array}{l}18-29 \text { vs. } 50+ \\
30-49 \text { vs. } 50+\end{array}$}} \\
\hline & & & & & & & & \\
\hline \multicolumn{9}{|l|}{ Males } \\
\hline $18-29$ years, $N=6$ & 8.91 & 0.70 & 4.20 & 0.98 & 4.71 & 0.72 & 53.13 & 9.02 \\
\hline $30-49$ years, $N=20$ & 8.98 & 0.76 & 4.40 & 0.87 & 4.58 & 0.62 & 51.24 & 7.41 \\
\hline $50+$ years, $N=13$ & 8.94 & 0.78 & 5.26 & 1.28 & 3.69 & 1.03 & 41.51 & 12.21 \\
\hline \multirow[t]{2}{*}{ ANOVA } & \multirow[t]{2}{*}{ N.S. } & & \multirow{2}{*}{\multicolumn{2}{|c|}{ N.S }} & \multirow{2}{*}{\multicolumn{2}{|c|}{$\begin{array}{l}18-29 \text { vs. } 50+ \\
30-49 \text { vs. } 50+\end{array}$}} & \multirow{2}{*}{\multicolumn{2}{|c|}{$\begin{array}{l}18-29 \text { vs. } 50+ \\
30-49 \text { vs. } 50+\end{array}$}} \\
\hline & & & & & & & & \\
\hline
\end{tabular}

TW, total width; MW, medullary width; $\mathrm{CT}$, cortical thickness; $\mathrm{Cl}$, cortical index; $\mathrm{N}$, number of individuals.

Significance measured at the 0.05 level. TW, MW, and $\mathrm{Cl}$ measured in $\mathrm{mm} . \mathrm{Cl}$ is a percentage (CW/TW $\times 100)$. $\mathrm{Cl}$ is significantly different at the 0.05 level between the sexes in the 18-29 years age group only.

variable. No significant sex differences were noted for percent cortical area (Ct.Ar/Tt.Ar $\times 100)$ in any age group.

\subsection{Second metacarpal radiogrammetry}

A detailed description of the broader radiogrammetry results can be found in the work by Beauchesne and Agarwal (2014), but are summarized here. Age differences were assessed for each sex separately using one-way ANOVA and Tukey's HSD post-hoc test. Results are summarized in Table 5. The results for the $\mathrm{Cl}$ measure are emphasized here as this measure has the greatest relevance to the comparative aims of this article, as $\mathrm{Cl}$ reflects an assessment of bone mass at that location, but also acts as a proxy for BMD in other regions of the body (Ives \& Brickley, 2005). Both males and females show significant age-related changes in $\mathrm{Cl}$. In both males and females, post-hoc tests indicate significant differences $(p<.05)$ between the older and both young and middle age groups, but not between young and middle age groups.

Sex-related differences for the $\mathrm{Cl}$ measure were also explored using Student's $t$-tests. In the youngest age category (18-29), females had a higher $\mathrm{Cl}$ than males. There is no statistically significant difference between males and females in the middle or older age groups.

\section{5 | DISCUSSION}

One of the first bioarchaeological studies to use multiple methods in the study of bone remodeling and loss was by Burr, Ruff, and Thompson (1990), who combined femoral cross-sectional geometry with histomorphometric analyses in their investigation of bone loss in the Pecos Indian population. The authors noted that physical activity probably played a protective role in Pecos females, and that medullary and intra-cortical bone loss was compensated geometrically through periosteal expansion (Burr et al., 1990). An important point of the paper was the complex relationship between the methods and that "confining the examination of bone only to gross geometric or only to microstructural factors may overlook the complete spectrum of bone adaptation to its environment" (Burr et al., 1990, p. 312). Robling and Stout (2003) pursued a similar study, combining measures of crosssectional geometry with histomorphometric analyses in order to explore how changes in physical activity affected the individuals of the archaeological Paloma population over time. Robling and Stout (2003) found a strong concordance between reductions in physical activity (via changing subsistence patterns) and reduced intra-cortical remodeling and geometric properties of the femur.

More recently, Peck and Stout (2007) explored bone mass, through cross-sectional measures of cortical area, between six skeletal elements in a small sample of cadaver samples in order to test the hypothesis that significant inter- and intra-skeletal variability exists. Although bone biologists have been aware of the heterogeneity of bone for some time (Chalmers \& Weaver, 1966; Frost, 1963; Melsen \& Mosekilde, 1981; Stevenson et al., 1986), it was argued that osteoporosis was largely (85\%) systemic and that any skeletal element could be used to assess bone mass (Nordin, Chatterton, Schultz, Need, \& Horowitz, 1996). What Peck and Stout (2007) have shown is that significant variability exists throughout skeletal elements and that this heterogeneity is largely due to particular mechanical loading histories. Further, variability was not different between sexes, age groups, or pathological and non-pathological groups (Peck \& Stout, 2007). Although this was a study with a small sample size, it demonstrated convincingly that more complex studies that account for skeletal heterogeneity are needed, for both clinical and archaeological populations. Gosman et al. (2011) have also contributed to this discussion by urging biological anthropologists to further engage with the complex changes that occur on the different bone envelopes (trabecular, endosteal, intracortical, and periosteal) over the life course. A key point of their article was that each bone surface potentially has age-specific remodeling responses to a number of biological, environmental, and cultural influences (Gosman et al., 2011). 


\section{$5.1 \mid$ Bone loss and the biocultural context of Velia}

Bone loss is influenced by numerous biocultural factors (Agarwal, 2008), so here we wish to situate the reader with a brief review of the biocultural context of Velia prior to our interpretation of the results of our study. Diet, reproductive history, and physical activity are the three factors that arguably deviate the most between archaeological and contemporary Western cultures. These three factors have been reviewed in detail by Beauchesne and Agarwal (2014) for the Velian context, but are summarized here.

Adequate nutrition was probably uncommon in the Roman world for most non-elite people (Garnsey, 1998). Diets were even poorer for infants, as they were weaned on to particularly poor quality foods (Garnsey, 1998). For adults, Roman diets in Italy tended to favor cereals and legumes, with limited animal protein intake (Garnsey, 1998). The isotopic dietary profile of all adults at Velia confirms this trend, with diets high in cereals and legumes, with a moderate intake of animal protein, and minimal consumption of marine protein (Craig et al., 2009). No age bias in diet was noted for adults. Although males did have access to more sources of protein on average, there is interestingly no clear evidence for completely gendered foodways, as a number of women in the sample had greater protein intakes than men. Access to higher quality protein sources may have had to do more with social class than gender.

Reproductive history is an important biocultural variable as clinical research has convincingly shown that while bone loss occurs during pregnancy and lactation, it is transitory and that high parity and extended breast-feeding may in fact have a positive effect on the female skeleton (Cumming \& Klineberg, 1993; Henderson, Sowers, Kutzko, \& Jannausch, 2000; Hillier et al., 2003; Kojima, Douchi, Kosha, \& Nagata, 2002; Lenora, Lekamwasam, \& Karlsson, 2009; Michaëlsson, Baron, Farahmand, \& Ljunghall, 2001; Paton et al., 2003; Sowers, 1996; Wiklund et al., 2011). It is critical then to consider how reproductive behavior might also have influenced bone loss in Roman women. What we know from numerous historical studies of the Roman period is that puberty was delayed compared to modern trends and that most women probably bore multiple children (Garnsey, 1998; Garnsey \& Saller, 1987; Harlow \& Laurence, 2002; Leftkowitz \& Fant, 1982). Breastfeeding practices are less clear, but historical and bioarchaeological studies provide compelling evidence that weaning would typically start at around three to six months of age, and end between the second and third years of life (Dupras \& Tocheri, 2007; Fuller, Molleson, Harris, Gilmour, \& Hedges, 2006; Garnsey, 1999; Prowse et al., 2008). Considered holistically, the typical Roman reproductive patterns of non-elite women indicate that the hormonal milieu throughout women's lives at Velia was considerably different from Western women living today (Beauchesne \& Agarwal, 2014).

Lastly, the role that physical activity has on the skeleton throughout life cannot be overstated. The level and type of physical activity that would have occurred at Velia is discussed by Beauchesne and Agarwal (2014). What is important to emphasize is that strenuous activity would have probably begun early in life (Dixon, 2001; Redfern, 2007; Sigismund-Nielsen, 2007) and would have persisted for much of the life course. Additionally, although a gendered division of labor would have been present for many occupations, non-elite women were not immune from difficult lives of manual labor and would have participated in maintaining agricultural crops and perhaps participated as unskilled laborers (Brunt, 1980; Erdkamp, 1999; Scheidel, 1996; Toner, 2002, 2009).

\section{2 | Changes in vertebral trabecular bone}

Age-related changes in trabecular microstructure at Velia are similar to modern populations in many regards, but some patterns do show important deviations. The number of trabeculae (Tb.N) was significantly different between age groups in both sexes. Conversely, the space between trabeculae (Tb.Sp) increased significantly with age in both sexes, paralleling age-related loss of Tb.N. This is expected based on findings of modern (Twomey, Taylor, \& Furniss, 1983) and archaeological investigations (Agarwal, 2008) as trabecular number and spacing are strongly negatively correlated. The Conn.D in trabeculae shows an agerelated change for both sexes, indicating that as individuals aged, the trabeculae became increasingly disconnected from each other. Sex differences in each age group were not present for either Tb.N or Tb.Sp, but for the Conn.D measure, a significant sex difference was found for both young and old age groups. In fact, Conn.D is the only measure of trabecular architecture where any significant sex differences were found. The importance of this finding is addressed further below.

The SMI measure showed that while trabeculae did shift from a more plate-like to rod-like model of bone, this change was not significant with age. It is difficult to directly compare the SMI findings in the Velia population to those of modern populations, as the methodologies and skeletal sites often differ. However, the role SMI plays in vertebral bone strength has been well identified (Fields, Eswaran, Jekir, \& Keaveney, 2009; Roux et al., 2010). Fields et al. (2009) found that when measures of bone mass are controlled for, SMI (along with trabecular thickness) is strongly predictive of whole bone vertebral strength. Roux et al. (2010) found that along with BMD, SMI and Tb.Th are strongly predictive of fracture risk. Sornay-Rendu, Boutroy, Munoz, and Bouxsein (2009) have also shown that in individuals with a history of fracture, trabecular architecture was significantly different than in controls without fractures. The Sornay-Rendu et al. (2009) study used limb bones, but the point that trabecular architecture contributes to whole bone strength remains. Duan, Seeman, and Turner (2001) noted that forward bending motions can create compression forces on vertebrae that are 10-fold than those from standing upright. In the Velian context, manual labor (e.g., dock worker), agriculture, and fishing would have necessitated repeated forward bending. Given that parameters of trabecular architecture are strongly related to biomechanical behavior (Fields et al., 2009), the SMI values for Velia suggest activity was high, and that this may have helped retain a more plate-like structure in vertebral trabecular bone with age than we see in modern groups who are far less physically active on average.

DA examines the changing direction of trabeculae with age (Njeh et al., 1999), and has also been shown to play a role in bone strength (Fields et al., 2009). This is because as vertebral trabecular bone ages, 
the organization of trabeculae change from a more isotropic state (equal strength in all directions) to more anisotropic one (Snyder et al., 1993). Anisotropy is considered an important part of bone strength but DA alone is a poor predictor of biomechanical activity and fracture (Wegrzyn et al., 2010). However, when combined with BV/TV and SMI, the three parameters explained $86 \%$ of the biomechanical variability and properties of the L3 vertebrae examined by Wegrzyn et al. (2010). The only current bioarchaeological report to examine DA in L4 vertebrae (or any vertebrae) is by Agarwal et al. (2004). In their study of Medieval peasants from Wharram Percy, the authors found that DA increased across the age groups, but like Velia, these differences were not significant. The values for DA, SMI, and Conn.D cannot be easily compared to published archaeological reports, as no study has yet examined these parameters together in vertebral bone in an archaeological context.

Of all the changes in trabecular architecture at Velia, perhaps the most interesting trend is that for both sexes, bone volume (BV/TV) did not decrease in a statistically significant way with age in either sex. This is unexpected, as clinical studies have shown BV/TV to decrease significantly with age, particularly in old age (Bergot, Laval-Jeantet, Preteux, \& Meunier, 1988; Riggs et al., 2008). BV/TV values did decrease across age groups however, so bone loss was taking place with age, but at an apparently reduced rate. Furthermore, the lack of sex differences, particularly in old age, is another important departure from the modern expectation that females will lose dramatically more bone than males in postmenopausal years (Riggs et al., 2008; Seeman, 2002). Parsing out the causative factors of bone maintenance and loss in archaeological contexts is difficult (Agarwal, 2008) and multiple lines of evidence are required.

Agarwal et al. (2004) reported a seemingly early age of bone loss at Wharram Percy, followed by stability of bone maintenance into old age, which is similar to what was observed for the Velia population. Agarwal et al. (2004) considered this pattern as unusual, as bone loss was expected in old age, not in younger individuals. However, more recent clinical work has shown that for both sexes, trabecular bone loss in the radius, tibia, and lumbar spine begins in young adulthood and decreases substantially prior to the decline in sex steroids in the sixth decade of life (Riggs et al., 2008). Similar findings were found for the lumbar spine in other archaeological populations as well (Kneissel et al., 1997; Vogel et al., 1990). However in the archaeological populations, although trabecular bone volume declined early in life, the loss of trabecular bone was less severe than in modern populations and it "stabilized" and did not dramatically worsen into postmenopausal years (Agarwal et al., 2004; Vogel et al., 1990). These archaeological findings mesh well with the findings by Riggs et al. (2008) who strongly affirm that the current clinical paradigms for the pathogenesis of osteoporosis are incomplete. In light of the work by Riggs et al. (2008), bioarchaeological investigations are perhaps well poised explore a suite of biocultural factors that might improve and refine the pathogenesis of osteoporosis.

Another important consideration in the analysis of BV/TV for the Velia population is the fact that apparent Tb.Th seems to have changed positively across age groups, particularly in males. The trends for Tb.N
Tb.Sp, and Conn.D suggest that BV/TV would decline significantly with age. However, the apparent general trend for Tb.Th to go up across age groups indicates that while trabeculae were being lost with age, the remaining trabeculae were thickened to compensate for this loss in numbers. This finding is not without precedent in clinical observations (Mosekilde, 1988; Nicholson et al., 1997; Roschger et al., 2001; Thomsen, Ebbesen, \& Mosekilde, 2002; Wegrzyn et al., 2010). Nicholson et al. (1997) observed that with increasing DA, the remaining trabeculae often thickened, probably to compensate for the loss of horizontal struts. The mechanism by which trabecular thickening might occur is still not fully understood, but the fact that vertically oriented trabeculae appear to thicken more commonly (Nicholson et al., 1997) suggests that the biomechanical forces are at least partly responsible. Nicholson et al. (1997) have argued that thickening could occur through a repair process, micro-calluses are accumulated over time.

\section{3 | Changes in rib intracortical bone}

Osteon size was quite uniform across the three age groups and for each sex. These results are consistent with a study by Pfeiffer (1998) who showed that osteon size is poorly correlated with sex or age. The mean osteon size for the Velia population as a whole was $29 \mu^{2}$, which is essentially equal what has been reported for a modern African American population, and to the archaeological population of Isola Sacra, who both have a mean osteon size of $30 \mu^{2}$ (Cho \& Stout, 2003). In contrast, a sample from modern European Americans from the Cho and Stout (2003) study had a mean osteon size of $50 \mu^{2}$ and was significantly different from both African Americans and the Isola Sacra and Velia populations. The biological significance of osteon size remains uncertain. Pfeiffer, Crowder, Harrington, and Brown (2006) tested the hypothesis that osteon size was related to biomechanical forces acting on the bone as a result of strenuous physical activity. The study compared femoral osteon sizes against those in the rib in a Later Stone Age population and a British historical population (Pfeiffer et al., 2006). The study found no consistent statistical relationship between osteon size and physical activity and/or metabolic activity (Pfeiffer et al., 2006). However, van Oers, Ruimerman, van Rietbergen, Hilbers, and Huiskes (2008) did report that in a modern population smaller osteon size was associated with strain load. More recently, Pfeiffer and Pinto (2012) have noted that the weight of the evidence does suggest a relationship between osteon size and activity, but that this relationship is likely complex and mediated by other factors. Some of these include fluctuations in local and systemic factors such as fluctuations in cytokines, vitamin D, calcitonin, estrogen, and parathyroid hormone (Pfeiffer et al., 2006).

OPD increased with age significantly in females, but not for males. A significant increase in OPD with age is expected as osteons accumulated in the cortex through continuous bone remodeling in life. The lack of significant increase in OPD with age in males may be explained by the very small sample size in the18-29 age group. Even with the poor sample size, statistical significance is nearly reached $(p=.08)$, suggesting that with a larger sample, male OPD would follow expected trends. Moreover, OPD increases most from the second to third decades, continues to increase in mid adulthood, but by roughly age 50 , it 
reaches an asymptote as the cortex begins to dramatically remodel out older osteons (Frost \& Wu, 1967; Stout \& Lueck, 1995; Stout \& Teitelbaum, 1976; Wu et al., 1970). Subsequently, it is not surprising to find only a small, but not significant increase in OPD between the 30-49 and $50+$ age groups, especially considering the limitations of skeletal age determination techniques. As seen with osteon size, sex differences were not present for OPD.

The mean OPD values for the Velia population are lower than other previously reported results (Cho \& Stout, 2003; Mulhern, 2000; Stout \& Lueck, 1995). Explaining the lower mean OPD values at Velia is difficult. One hypothesis is that the rib cortices of Velia were thinner and may have biased sampling of osteons and thus affected OPD. Osteon distribution is highly variable (Pfeiffer, 1998) and thinner rib cortices (percent cortical area) may have affected OPD. However, when percent cortical area is considered, the mean for Velia for percent cortical area is $34.6 \%$, which is well within the range of other studies (Cho \& Stout, 2003). Subsequently, it is difficult to attribute the OPD values at Velia to sampling error. Given that OPD is intimately tied to Ac.F and bone formation rate, the discussion will now move to discussing those measures and what the significance of those remodeling parameters might mean.

The Ac.F results for Velia closely follow trends published for other archaeological populations (Cho \& Stout, 2003; Mulhern, 2000; Stout \& Lueck, 1995), in that Ac.F changes significantly with age in both sexes. This is expected, as Ac.F would only increase in adulthood under unusual metabolically induced demands on the skeleton (Martin \& Burr, 1989). However, Cho and Stout (2011) note that hormonal changes from menopause can increase Ac.F in females. For Velia, females in young and middle age created more osteons annually per $\mathrm{mm}^{2}$ than males, but this was not statistically significant. Comparatively, the mean Ac.F closest to Velia $\left(0.83 \# / \mathrm{mm}^{2} /\right.$ year) is from a sample of modern Africa Americans, who have slightly lower Ac.F (0.79 \#/mm²/year) (Cho \& Stout, 2003). The Isola Sacra sample, which is culturally most similar to the population of Velia, has a mean Ac.F that is substantially higher $\left(0.97\right.$ \#/ $\mathrm{mm}^{2} /$ year $)$ than Velia.

While Ac.F represents the number of new osteons created annually per $\mathrm{mm}^{2}$, BFR is a product of Ac.F and mean osteon size and thus represents the average amount of bone formed annually per $\mathrm{mm}^{2}$ in a particular bone. BFR at Velia decreased significantly with age in both sexes. In both sexes, BFR changed significantly across every age group. Significant changes with age were also noted in other archaeological and modern populations (Cho \& Stout, 2003; Mulhern, 2000; Stout \& Lueck, 1995). Sex differences in BFR were also statistically explored and none were noted. This also matches the trends in published reports that find no difference in BFR between the sexes (Cho \& Stout, 2003; Mulhern, 2000).

The remodeling patterns in the Velia sample highlight the uniqueness of the population. Mean rib osteon sizes were normal, but on the smaller end of what have been reported in archaeological samples. The density of osteons per $\mathrm{mm}^{2}$ was also low, including the rate at which they were formed per year. What the results from bone osteon size and formation rate likely show is that in addition to a lower activation of new osteons per year, less osteonal bone was formed during this turnover. This is consistent with evidence that osteon size is affected by the activity and longevity of osteoblasts during bone formation (Qiu, Rao, Palnitkar, \& Parfitt, 2009). As such, bone remodeling, on average, was reduced compared to a number of modern and archaeological populations, including Isola Sacra (Cho \& Stout, 2003), which based on historical and bioarchaeological reconstructions, was likely similar to Velia in many, but not all regards. Finally, Haversian canal size did not increase significantly with age $(p=.137)$ and there are no significant sex differences as well. It is expected that Haversian canal size would increase significantly with age as osteoblast function declines and less bone is filled in after each remodeling event (Mundy, 1995). However, Stein, Feik, Thomas, Clement, and Wark (1999) caution that correlations between age and Haversian canal size have been quite variable and that this relationship is still uncertain.

There are a number of key implications relating to the remodeling dynamics of the Velia population. Low OPD values for Velia do not pose much of a concern, as lower OPD values are expected in archaeological populations (Mulhern, 2000). Stout and Lueck (1995) have argued that the common observation of lower OPD in archaeological groups may be related to a longer growth period and that skeletal maturity is reached much later than when compared to modern populations. Stout and Lueck (1995) hypothesize that with lower OPD, Ac.F and bone formation rate would be lower as well, given that the agedependent constant for the "effective age of adult bone" is 12.5 and based on modern samples. For the Velia sample combined, both Ac.F and bone formation rate were indeed low, suggesting that growth may have been prolonged at Velia, perhaps due to physiological stress during childhood. The Velia population does have a high prevalence of dental enamel hypoplasias in adults, strongly indicative of childhood stress (Beauchesne, 2012). Furthermore, skeletal growth profiles from children aged 3 months to 12 years strongly also convincingly support a pattern of physiological stress during growth, thus prolonging maturity (Beauchesne, 2012).

Frost (1987c) and others (Parfitt, 2003; Rauch, 2005, 2007; Schoenau, Fricke, \& Rauch, 2003) have also noted the important connection of mechanical usage to bone health, particularly in growth and development. An older "effective age of adult bone" could be a product of extended modeling during growth and development, increasing the amount of bone gained during childhood and adolescence (Mulhern, 2000). This can be seen as an adaptation to a very mechanically active lifestyle (Mulhern, 2000), particularly during important growth years. As Frost (1987c) has shown, increased activity during growth would extend the modeling period, and if physical strains were high for a population, this would decrease the "effective age of adult bone." High levels of activity at younger ages may also help explain lower remodeling parameters later in life. Parfitt et al. (1997) have argued that the development of more bone early in life could result in reduced levels of fatigue and bone micro-damage later in life, which would require less remodeling to repair micro-cracks and overall lower bone turnover rates.

Mulhern (2000) has also noted that the minimum effective strain (MES) set point required to repress bone remodeling should also be 
considered when comparing remodeling dynamics between populations. If strains are repeatedly applied above the MES, Ac.F and bone formation rates are suppressed, although if activity reaches extreme levels Ac.F increases in order to repair micro-damage to prevent failure of the bone (Frost, 1987c). Conversely, if disuse of bone falls below a set threshold, remodeling rates increase but do not fully replace the bone that is resorbed in order to remove bone that is not being used (Frost, 1987c, 2003). Frost (2003) adds that much of the bone lost during disuse remodeling would occur from trabecular or endocortical regions. This can be seen in the values for Ac.F and rib medullary area in modern European Americans, who have high values for both (Cho \& Stout, 2003). What the historical and skeletal data show is that activity, and subsequently repeated strains on the skeleton, was likely quite elevated for the Velia population. This constant strain may have surpassed the MES required to suppress Ac.F and bone formation rates in many individuals, explaining these low remodeling parameters in the Velia population throughout adulthood.

While these hypotheses explaining the low remodeling rates in the Velia population have merit, there are some limiting factors. First, the rib is not representative of a more physically active skeletal element like the femur (Robling \& Stout, 2003). In order to fully test the role physical activity may have had on bone mass, the histomorphometric variables used in this study should be assessed in femoral and humeral samples and explored to see whether the trends observed in the ribs still hold. It is important to also note that the rib is subject to continuous low strains at high frequency, and this should result in higher remodeling rates in the rib than in the femur in order to repair accumulated micro-cracks (Martin, Burr, \& Sharkey, 1998; Sobelman et al., 2004). However, Robling and Stout (2003) have observed higher remodeling rates in the femur. Cho and Stout (2011) note that sampling methodology, particularly in the femur, can affect results, so there is still some debate if rib remodeling is always more advanced than in the femur. The rib remodeling dynamics from Kulubnarti (Mulhern, 2000) were quite similar to Velia in many regards and in that study remodeling in the ribs was also compared to femoral remodeling. At Kulubnarti, evidence of increased physical activity through femoral remodeling is consistent with remodeling in the rib (Mulhern, 2000), which suggests that rib remodeling might act as a good general proxy for general physical activity throughout the body if femoral or humeral thin sections are not available. It is also important to consider that while daily physical activity was undoubtedly high at Velia, it is impossible to assess whether or not activity was substantially lower than in other historic populations, all of which also depended on manual labor for survival. Lastly, sample size for the histomorphometric analysis was modest, and notably small for young males, so the possibility remains that confounding factors due to sampling size affect these results.

\section{4 | Changes in metacarpal and rib cross-sectional areas}

The age- and sex-related patterns of metacarpal cortical bone maintenance and loss at Velia generally follow modern population trends. Both sexes reach peak bone mass in young adulthood (Böttcher et al.,
2006) and Velian females reach a higher mean peak $\mathrm{Cl}$ than males, which is consistent with modern patterns of bone growth (Böttcher et al., 2006; Maggio et al., 1997; Szulc, Seeman, Duboeuf, SornayRendu, \& Delmas, 2006). Medullary spaces were smaller in females than in males in the young age group, supporting clinical observations that bone is preferentially deposited on the endosteal surface in young aged females in anticipation of the metabolic requirements of pregnancy and lactation (Martin, 2003).

Changes in TW were not consistent between the sexes. Females showed an increase in TW between young and middle age, but this difference was not significant. Males remained largely stable across age groups. This is unexpected as periosteal expansion in metacarpals is typically greater in males in modern populations (Böttcher et al., 2006). We hypothesized previously (Beauchesne \& Agarwal, 2014) that these findings may imply that females at Velia had a delayed exposure to strenuous physical activity, explaining the small increase in TW from young to middle age, while males may have experienced high levels of physical activity much earlier in life and consistently across the life cycle.

Following trends in modern populations, medullary expansion (due to resorption on the inner surfaces of the metacarpals) was the primary cause of cortical thinning in the metacarpal (Maggio et al., 1997; Szulc et al., 2006). This is not surprising given that large increases in male MW prior to older age $(60+)$ are typically not seen in modern populations (Böttcher et al., 2006; Maggio et al., 1997), and this is consistent with our findings. Additionally, increases in $\mathrm{MW}$ across age groups were proportionally met with decreases in CT in both sexes.

The $\mathrm{Cl}$ measure is in many ways the most useful as it controls body size (Ives \& Brickley, 2005). Recently, Glencross and Agarwal (2011) have shown that controlling for body size was more accurate by dividing CT by bone length instead of TW. This updated methodology was performed on these data, but not reported here as most other radiogrammetry studies have used the standard $\mathrm{Cl}$ measure and we wished to facilitate future comparisons. However, it is important to note that no significant differences in our findings or conclusions were found using the revised index by Glencross and Agarwal (2011). The most important finding in the $\mathrm{Cl}$ results, and where our data differ significantly from modern observations, is the lack of a statistically significant sex difference for all age groups.

Changes to bone mass in the rib are also important to consider. In both the rib and the metacarpal, significant decline in percent cortical bone was noted. Between-sex comparisons in bone mass also yielded similar results, with no sex differences observed in either the rib or metacarpal. However, closer investigations do reveal some key differences in bone loss between the skeletal regions. Explorations of bone loss in our sample using the Meema and Meema (1987) method, which labels individuals as abnormal if their cortical index falls below two standard deviations of the young adult mean, found fairly consistent age- and sex-related patterns between the bone sites. The one exception for the Velia sample is for females in the oldest age group, who had twice the amount of individuals with abnormal bone in the metacarpal versus the rib. At first glance this appears counterintuitive; given 
the more biomechanically involved nature of the metacarpal one would expect ribs to have advanced bone loss over the hand. However, if we examine the percentage of bone retained from young age (following Mays, 2006), we see the second metacarpal at Velia retains more bone into old age than the ribs in both sexes and for middle and old aged adults. Bone loss in the metacarpal occurs predominantly in old age $(50+)$, while in the ribs cortical bone loss occurs earlier (30-49 age range).

Another important measure of bone strength in the rib is the parabolic index (Cho \& Stout, 2003; Epker \& Frost, 1964; Takahashi \& Frost, 1966). The parabolic index measures the amount of cortical bone around the marrow space and has an optimum value of 0.25 (Epker \& Frost, 1964). The Epker and Frost (1964) study established that individuals with a parabolic index of less than 0.19 were osteoporotic, and in the Velia population, none of the mean values for any age or sex fall below this score. Significant age related decline in the parabolic index was noted for both females $(p=.01)$ and males $(p=.03)$, as observed in a larger modern sample (Takahashi \& Frost, 1966). However, no sex differences were noted for any age group in the Velia, contrary to the results by Takahashi and Frost (1964). For the Roman Isola Sacra population, Cho and Stout (2003) also noted a lack of sex differences. Interestingly, in the modern sample (Takahashi \& Frost, 1966), females retain a higher parabolic index than males in young adulthood until very old age $(70+)$, where index values between the sexes realign. For the Velia sample, the parabolic indices are nearly identical throughout life, which may help explain the near nonexistence of fragility fractures at Velia.

\section{$5.5 \mid$ An argument for multi-method approaches}

The characterization of long-term bone maintenance and loss at Velia can be summarized as mostly typical and what we expect based on observations in modern (Böttcher et al., 2006; Maggio et al., 1997; Szulc et al., 2006) and archaeological (Mays, 1996, 2006) samples. Broadly speaking, bone quantity is highest in young adulthood and then declines significantly with age. One fundamental difference between the trends at Velia and in modern populations is that no sex differences were noted for the cortical index in metacarpals, relative cortical area in ribs, parabolic index in ribs, bone volume in vertebral trabecular bone, and any histomorphometric measure of rib cortical bone. Compared to modern populations, young adult means for $\mathrm{Cl}$ are lower than a modern Finnish population (Virtama \& Helelä, 1969), but higher than another modern German sample (Böttcher et al., 2006). Typically, peak bone mass, and thus a measure such as $\mathrm{Cl}$, would be expected to be lower in the past because of common nutritional deficiencies (Mays, 1996). Following the clinical work linking early life events and adult fracture risk (Cameron \& Demerath, 2002; Cooper et al., 2002; Cooper et al., 2006; Dennison, Syddall, Sayer, Gilbody, \& Cooper, 2005; Gale, Martyn, Kellingray, Eastell, \& Cooper, 2001), one would expect extremely poor quality bone and frequent fragility fractures in archaeological populations given the typically poorer quality nutrition and common physiological stresses. However, the patterns of bone loss in the Velia population, as well as other archaeological populations, do not always bear this out. Nutrition was undoubtedly poorer in the Roman context Velia was part of (Garnsey, 1998), so an argument for the crucial role that physical activity played during adolescence is strengthened by the observation that $\mathrm{Cl}$ at Velia in young adults surpassed those of a modern European population (Böttcher et al., 2006). These arguments are supported by the mid- and shortterm remodeling in ribs and vertebrae as well. Percent cortical area was very high in young adult ribs, and indicators of remodeling activity were typically lower than other archaeological and modern populations (Cho \& Stout, 2003). Bone volume (BV/TV) in both males and females at young age was higher at Velia than in a modern normative study (Compston, 1999). Together, this suite of measures implies a longer period growth, but also a significant effect from high strains induced from physical activity (Frost, 1987c), as we would expect worse bone mass given the nutritional and physiological challenges presented to children early in life at Velia (Beauchesne, 2012).

Important differences between the skeletal sites begin to emerge when middle and old aged adults are considered. In the second metacarpal, bone loss in females begins to occur typically earlier than is observed in modern populations (Böttcher et al., 2006; Maggio et al., 1997; Szulc et al., 2006; Virtama \& Helelä, 1969). This would suggest muscular disuse (Frost, 1987c), but lines of evidence from other skeletal sites suggest otherwise. Remodeling activity remains low in middle age, which probably meant that biomechanical strains were elevated. Further, measures of trabecular bone, particularly BV/TV, SMI, and Tb. Th, also indicated that vertebrae were being substantially loaded. Therefore, the drop in $\mathrm{Cl}$ into middle age, occurring primarily in females, while not severe, might be better explained by other biocultural factors such as temporary bone loss due to pregnancy and lactation. For example, many in this age group may have died during pregnancy and/or lactation. Moreover, bone loss with pregnancy and lactation has been noted in other archaeological studies but it is considered to be transitional and temporary (Agarwal et al., 2004), although Mays (2010) argues that this may not always be the case.

Cortical index in older adults was significantly different than in young and middle aged adults for both sexes. Interpreted in light of the shorter and mid-level remodeling, activity seems to have remained relatively high and this change in $\mathrm{Cl}$ should be seen as caused by other factors. BV/TV did not change significantly with age and the trends observed in analyses of trabecular architecture, such as increasing trabecular thickness, suggest that day-to-day activities remained strenuous into old age. Remodeling activity in the ribs was low in old age, but this is expected and normal to some extent (Mulhern, 2000), so histomorphometric analyses become less useful here. Ultimately what the changes in cortical index show is that even if physical activity was high and sustained throughout life, hormonal changes during the aging process cannot be fully mediated and still have a large effect on bone loss in some areas of the skeleton.

\subsection{Study limitations and future directions}

In a bioarchaeological investigation such as this one, there are a number of methodological limitations that should be considered in the 
interpretive process. Our assessments of rib cortices did not account for porosity (Agnew \& Stout, 2012), which in some individuals can have a significant effect (nearly $12 \%$ difference) on assessments of percent cortical bone present. However, in most individuals the difference between measures of cortical area before and after removing porosity is minimal (Lipps, 2014), typically under 4\% (Agnew \& Stout, 2012). Although this study did not include porosity in its analysis, the concerns raised by Agnew and Stout (2012) are valid and the long-term effects of seemingly minor variations in porosity may have substantial effects on fracture risk over the life course. Porosity should be explored in greater detail with future histomorphometric study. It is also important to note that since trabecular bone is more sensitive to metabolic changes than cortical bone, it is also more sensitive to the effects of age, particularly in the $50+$ oldest age group. Our inability to accurately estimate age-at-death in individuals over 50 thus presents a problem for interpretations of trabecular bone loss in older individuals as the effects of menopause and age cannot be easily separated.

All bioarchaeological studies are cross-sectional in nature, and thus reflect, in any particular measure of bone, a snapshot in time. Larger sample sizes can help mitigate some of the limitations of crosssectional studies, but poor preservation, differential burial, and excavation techniques all operate to limit sample sizes bioarchaeology (Jackes, 2011). Sample size varied for this study, depending on the analysis in question, but was quite good overall for a bioarchaeological investigation using multiple methods. Concerns over sample size were noted throughout where appropriate.

Selective mortality and frailty (Wood et al., 1992) are potential confounding factors in all bioarchaeological research. The design of this project, primarily through the use of multiple lines of evidence (Larsen, 2002), was selected in part to minimize these effects. The use of multiple lines of evidence removes some of the potential bias given that a convergence of data from different measures along a single path partially controls for some of the effects of selective mortality and frailty (DeWitte \& Stojanowski, 2015; Milner, Wood, \& Boldsen, 2008; Wood et al., 1992; Wright \& Yoder, 2003), as well as variable sample sizes. Third, a good understanding of a population's diet and weaning practices can also help control for factors of selective mortality and frailty (Wright \& Yoder, 2003). Dietary profiles, via stable isotope analysis, are available for this population (Craig et al., 2009) and were considered in assessments of age and sex group dietary profiles that may have increased their frailty. Culture has an important role in determining hidden heterogeneity and its effects on selective mortality (Wright \& Yoder, 2003) and it is argued that the biocultural emphasis of this project helped alleviate some of the concerns raised by Wood et al. (1992).

We also acknowledge that poor preservation is a higher risk for histomorphometry and analyses trabecular architecture than for measures of whole bone, such as radiogrammetry. The central issue is that the quality of histological slides or trabeculae cannot be assessed in the field. This is a potentially time consuming and expensive risk, one that we feel has limited multi-method approaches to date, and understandably so. The methods that were chosen for this research were selected for their potential to inform, but also because they are the most commonly used in bioarchaeological investigations of bone loss (Gosman et al., 2011). However, even examining multiple bone elements with simple cross-sectional area measures has been shown to be highly informative about intra- and inter-skeletal variability in bone mass (Peck \& Stout, 2007). We urge researchers in future studies to account for the heterogeneity of the skeleton by either employing multiple methods as we have done here, if possible, or by sampling across different skeletal elements with a single methodology. Lastly, future studies should employ a more comparative approach between populations, so that the influence of biocultural variables that differ between the groups, such as activity, can be better understood. Similarly, populations that are highly stratified would be useful as well.

\section{6 | CONCLUSIONS}

The primary goal of this study was to provide a comprehensive bioarchaeological investigation of bone maintenance and loss in the Velia population to examine how the results from a multi-method approach might differ from traditional studies employing only one method. The multi-method approach revealed some important findings regarding bone health at Velia. First, the Velia population is similar to contemporary populations in many ways. Sex-related patterns of cortical bone deposition showed expected differences that result from the divergent hormonal pathways between the sexes. In addition, the metacarpal radiogrammetry and histomorphometry analyses showed significant age-related changes in bone loss and turnover. Many of the observed changes in the measures of bone loss in trabecular architecture are also consistent with contemporary populations. Nevertheless, although patterns of bone loss at Velia are similar to living populations in many ways, a number of observations distinguish the patterns from contemporary observations. For example, trabecular bone volume did not decrease significantly with age, which is expected clinically. In addition, only one female and one male with clear signs of osteoporosis-related fragility fractures could be identified. But perhaps the most meaningful observation is that no statistically significant sex differences were recorded, except for one measure of trabecular bone microarchitecture (Conn.D). This is an important finding as it adds to existing bioarchaeological observations that sex differences in the past should not be taken as an a priori assumption (Agarwal, 2012).

Explaining the differences in patterns of bone loss between populations is difficult. However, the variable patterns of bone maintenance fragility in the past should not come as a surprise, given that groups in the past would have had very different biosocial histories from our own. The variability in bone maintenance and loss across the skeleton observed in archaeological samples is an important research avenue, and illustrates the biocultural nature of plasticity and development of the body. Bioarchaeological studies remind us that the modern causes and prevalence of bone loss and fragility are situated in a particular social and temporal context. Our modern lifestyle, throughout our life course, is often dramatically different than that experienced throughout most of human history. Using a multi-method approach can reveal 
differential timing of bone loss between elements, and detailed considerations of biocultural context can then help explain the timing of these bone loss events. This process captures a more complete picture of bone health than looking at any singular skeletal element with a single method of measurement. The use of multiple methods is an important step forward in studies of bone loss as the approach embraces the fact that the human skeleton is not homogeneous structure but shows great variability throughout the body over the life course (Gosman et al., 2011).

\section{ACKNOWLEDGMENTS}

The authors are grateful to the anonymous reviewers and to the Editor for their comments and suggestions. This project was supported through a Social Sciences and Humanities Research Council of Canada doctoral fellowship (P.B.), Stahl research grant (P.B) and the COR UC Berkeley faculty grant (S.C.A). Authors would like to extend their sincere thanks to Dr. Luca Bondioli, Alessandra Sperduti, and the staff of the National Museum of Prehistory and Ethnography "Luigi Pigorini" (Section of Anthropology) in Rome for access to and invaluable assistance in analyzing the Velia skeletal collection. They also thank Dr. Roger Byrne and Liam Ready in the Department of Geography, UC Berkeley for their assistance with the radiography, and Dr. Sharmila Majumdar and Andrew Burghardt for their invaluable assistance in their analyses of trabecular bone at UCSF.

\section{REFERENCES}

Acsàdi, G., \& Nemeskèri, J. (1970). History of human life-span and mortality. Budapest: Akàdemiai Kiadò.

Agarwal, S. (2008). Light and broken bones: Examining and interpreting bone loss and osteoporosis in past populations. In S. R. Saunders, \& M. A. Katzenberg (Eds.), Biological anthropology of the human skeleton (pp. 387-410). New York: Wiley-Liss.

Agarwal, S. C. (2012). The past of sex, gender, and health: Bioarchaeology of the aging skeleton. American Anthropologist, 114, 322-335.

Agarwal, S. C. (2016). Bone morphologies and histories: Life course approaches in bioarchaeology. Yearbook of Physical Anthropology, 159, S130-S149.

Agarwal, S., \& Beauchesne, P. (2011). It is not carved in bone: Development and plasticity of the aged skeleton. In S. C. Agarwal, \& B. Glencross (Eds.), Social bioarchaeology (pp. 312-332). New York: Wiley-Blackwell.

Agarwal, S. C., \& Grynpas, M. D. (1996). Bone quantity and quality in past populations. Anatomical Record, 246, 423-432.

Agarwal, S. C., \& Grynpas, M. D. (2009). Measuring and interpreting agerelated loss of vertebral bone mineral density in a medieval population. American Journal of Physical Anthropology, 139, 244-252.

Agarwal, S. C., \& Stout, S. (2003). Bone loss and osteoporosis: An anthropological perspective. New York: Kluwer Plenum Academic Press.

Agnew, A. M., \& Stout, S. D. (2012). Brief communication: Reevaluating osteoporosis in human ribs: The role of intracortical porosity. American Journal of Physical Anthropology, 148, 462-466.

Agarwal, S. C., Dumitriu, M., Tomlinson, G. A., \& Grynpas, M. D. (2004). Medieval trabecular bone architecture: The influence of age, sex, and lifestyle. American Journal of Physical Anthropology, 124, 33-44.
Barak, M. M., Lieberman, D. E., \& Hublin, J. J. (2011). A wolf in sheep's clothing: Trabecular bone adaptation in response to changes in joint loading orientation. Bone, 49, 1141-1151.

Barnett, E., \& Nordin, B. E. (1960). The radiological diagnosis of osteoporosis: A new approach. Clinical Radiology, 11, 166-174

Beauchesne, P. (2012). Physilogical stress, bone growth and development in Imperial Rome (Doctoral Dissertation). UC, Berkeley.

Beauchesne, P., \& Agarwal, S. C. (2014). Age-related cortical bone maintenance and loss in an Imperial Roman population. International Journal of Osteoarchaeology, 24, 15-30.

Becker, D. J., Killgore, M. L., \& Morrisey, M. A. (2010). The social burden of osteoporosis. Current Rheumatology Reports, 12, 186-191.

Bencivenga, T. C. (1990). Elea: Problems of the relation between city and territory. In J. P. Descoeudres (Ed.), Greek colonists and native populations: Proceedings of the First Australian Congress of Classical Archaeology (pp. 365-371). Oxford: Clarendon Press.

Bergot, C., Laval-Jeantet, A. M., Preteux, F., \& Meunier, A. (1988). Measurement of anisotropic vertebral trabecular bone loss during aging by quantitative image analysis. Calcified Tissue International, 43, 143-149.

Birnbaum, E. (1992). Osteoporosis: A summary of recent literature. Chronic Diseases in Canada, 13, 89-95.

Bonjour, J., Chevalley, T., \& Ferrari, S. (2007). Gene-environment interactions in the skeletal response to nutrition and exercise during growth. In R. Daly, \& M. Petit (Eds.), Optimizing bone mass and strength. The role of physical activity and nutrition during growth (pp. 64-80). Basel: Karger Publishers.

Bonjour, J. P., Chevalley, T., Ammann, P., Slosman, D., \& Rizzoli, R. (2001). Gain in bone mineral mass in prepubertal girls 3.5 years after discontinuation of calcium supplementation: A follow up study. Lancet, 358, 1208-1212.

Boonen, S., Nijs, J., Borghs, H., Peeters, H., Vanderschueren, D., \& Luyten, F. P. (2005). Identifying postmenopausal women with osteoporosis by calcaneal ultrasound, metacarpal digital $\mathrm{X}$-ray radiogrammetry and phalangeal radiographic absorptiometry: A comparative study. Osteoporosis International, 16, 93-100.

Böttcher, J., Pfeil, A., Schäfer, M. L., Petrovitch, A., Seidl, B. E., Mentzel, H. J., ... Kaiser, W. A. (2006). Normative data for digital X-ray radiogrammetry from a female and male German cohort. Journal of Clinical Densitometry, 9, 341-350.

Brickley, M. (2002). An investigation of historical and archaeological evidence for age-related bone loss osteoporosis. International Journal of Osteoarchaeology, 12, 364-371.

Brickley, M., \& Agarwal, S. C. (2003). Techniques for the investigation of age-related bone loss and osteoporosis in archaeological bone. In S. C. Agarwal, \& S. D. Stout (Eds.) Bone loss and osteoporosis: An anthropological perspective, (pp. 157-172). New York: Kluwer Plenum Academic Press.

Brickley, M., \& Ives, R. (2008). The bioarchaeology of metabolic bone disease. London: Elsevier.

Brooks, S., \& Suchey, J. (1990). Skeletal age determination based on the os pubis, a comparison of the Ascàdi-Nemeskèri and Suchey-Brooks methods. Human Evolution, 5, 227-238.

Brothwell, D. R. (1981). Digging up bones (3rd ed.). Ithaca: Cornell University Press.

Brunt, P. (1980). Free labour and public works at Rome. Journal of Roman Studies, 70, 81-100.

Buikstra, J. E., \& Ubelaker, D. H. (1994). Standards for data collection from human skeletal remains. Fayetteville: Arkansas Archaeological Survey Research Series No. 44. 
Burr, D. B., Ruff, C. B., \& Thompson, D. D. (1990). Patterns of skeletal histologic change through time: Comparison of an archaic native American population with modern populations. Anatomical Record, 226, 07-13.

Cameron, N., \& Demerath, E. (2002). Critical periods in human growth and their relationship to diseases of aging. American Journal of Physical Anthropology, 119, 159-184.

Carballido-Gamio, J., \& Majumdar, S. (2006). Clinical utility of microarchitecture measurements of trabecular bone. Current Osteoporosis Reports, 4, 64-70.

Center, J., \& Eisman, J. (1997). The epidemiology and pathogenesis of osteoporosis. Clinical Endocrinology and Metabolism, 11, 23-62.

Chalmers, J., \& Weaver, J. K. (1966). Cancellous bone: Its strength and changes with aging and an evaluation of some methods for measuring its mineral content. Journal of Bone and Joint Surgery, 48, 299-308.

Chamberlain, A. (2000). Problems and prospects in paleodemography. In M. Cox, \& S. Mays (Eds.), Human osteology in archaeology and forensic science (pp. 101-116). Cambridge: University Press.

Chirchir, H., Kivell, T. L., Ruff, C. B., Hublin, J. J., Carlson, K. J., Zipfel, B., \& Richmond, B. G. (2015). Recent origin of low trabecular bone density in modern humans. Proceedings of the National Academy of Sciences United States of America, 112, 366-371.

Cho, H., \& Stout, S. D. (2003). Bone remodeling and age-associated bone loss in the past: A histomorphometric analysis of the Imperial Roman skeletal population of Isola Sacra. In S. C. Agarwal, \& S. D. Stout (Eds.) Bone loss and osteoporosis: An anthropological perspective (pp. 207-228). New York: Kluwer Academic/Plenum Publishers.

Cho, H., \& Stout, S. D. (2011). Age-associated bone loss and intraskeletal variability in the Imperial Romans. Journal of Anthropological Sciences, 89, 109-125.

Christodoulou, C., \& Cooper, C. (2003). What is osteoporosis? Postgraduate Medical Journal, 79, 133-138.

Compston, J. (1999). Histomorphometric manifestations of age-related bone loss. In C. J. Rosen, L. Glowacki, \& J. P. Bilezikian (Eds.), The aging skeleton (pp. 251-262). San Diego: Academic Press.

Cooper, C., Javaid, M. K., Taylor, P., Walker-Bone, K., Dennison, E., \& Arden, N. (2002). The fetal origins of osteoporotic fracture. Calcified Tissue International, 70, 391-394.

Cooper, C., Westlake, S., Harvey, N., Javaid, K., Dennison, E., \& Hanson, M. (2006). Review: developmental origins of osteoporotic fracture. Osteoporosis International, 17 (3), 337-347.

Craig, O. E., Biazzo, M., O'connell, T. C., Garnsey, P., Martinez-Labarga, C., Lelli, R., ... Bondioli, L. (2009). Stable isotopic evidence for diet at the Imperial Roman coastal site of Velia (1st and 2nd Centuries AD) in Southern Italy. American Journal of Physical Anthropology, 139, 572-583.

Crowe, F., Sperduti, A., O'connell, T. C., Craig, O. E., Kirsanow, K., Germoni, P., ... Bondioli, L. (2010). Water-related occupations and diet in two Roman coastal communities (Italy, first to third century $A D$ ): Correlation between stable carbon and nitrogen isotope values and auricular exostosis prevalence. American Journal of Physical Anthropology, 142, 355-366.

Cumming, R. G., \& Klineberg, R. J. (1993). Breastfeeding and other reproductive factors and the risk of hip fractures in elderly women. International Journal of Epidemiology, 22, 684-691.

Cummings, S. R., Nevitt, M. C., Browner, W. S., Stone, K., Fox, K., Ensrud, K. E., ... Vogt, T. M. (1995). Risk factors for hip fracture in white women. New England Journal of Medicine, 332, 767-773.

Dempster, D. W. (2011). Osteoporosis and the burden of osteoporosisrelated fractures. The American Journal of Managed Care, 17, s164s169.
Dennison, E. M., Syddall, H. E., Sayer, A. A., Gilbody, H. J., \& Cooper, C. (2005). Birth weight and weight at 1 year are independent determinants of bone mass in the seventh decade: The Hertfordshire cohort study. Pediatric Research, 57, 582-586.

DeWitte, S. N., \& Stojanowski, C. M. (2015). The Osteological Paradox 20 years later: Past perspectives, future directions. Journal of Archaeological Research, 23, 397-450.

Dey, A., McCloskey, E. V., Taube, T., Cox, R., Pande, K. C., Ashford, R. U., ... Kanis, J. A. (2000). Metacarpal morphometry using a semiautomated technique in the assessment of osteoporosis and vertebral fracture risk. Osteoporosis International, 11, 953-958.

Dixon, S. (2001). Reading Roman women. London: Bristol Classical Press.

Duan, Y., Seeman, E., \& Turner, C. H. (2001). The biomechanical basis of vertebral body fragility in men and women. Journal of Bone Mineral Research, 12, 2276-2283.

Dupras, T., \& Tocheri, M. (2007). Reconstructing infant weaning histories at Roman period Kellis, Egypt using stable isotope analysis of dentition. American Journal of Physical Anthropology, 134, 63-74.

Ekenman, I., Eriksson, S. A., \& Lindgren, J. U. (1995). Bone density in medieval skeletons. Calcified Tissue International, 56, 355-358.

Epker, B. N., \& Frost, H. M. (1964). The parabolic index: A proposed index of the degree of osteoporosis in ribs. Journal of Gerontology, 19, 469-473.

Erdkamp, P. (1999). Agriculture, underemployment and the cost of rural labour in the Roma world. The Classical Quarterly, 49, 566-572.

Fiammenghi, C. A. (2003). La Necropoli di Elea-Velia: Qualche osservazione preliminare. In M. Grecia (Ed.), Elea-Velia. Le Nuove ricerche, Quaderni del Centro Studi (pp. 49-61). Pozzuoli: Italy.

Fields, A. J., Eswaran, S. K., Jekir, M. G., \& Keaveney, T. M. (2009). Role of trabecular microarchitecture in whole-vertebral body biomechanical behavior. Journal of Bone and Mineral Research, 24, 1523-1530.

Fonseca, H., Moreira-Gonçalves, D., Coriolano, H. A., Duarte, J. A. (2014). Bone Quality: The Determinants of Bone Strength and Fragility. Sports Medicine, 44(1), 37-53.

Frost, H. (2001). Why should many skeletal scientists and clinicians learn the Utah paradigm of skeletal physiology? Journal of Musculoskeletal and Neuronal Interactions, 2, 121-130.

Frost, H. (2003). On changing views about age-related bone loss. In S. C. Agarwal, \& S. D. Stout (Eds.), Bone loss and osteoporosis: An anthropological perspective (pp. 19-30). New York: Kluwer Plenum Academic Press.

Frost, H. M. (1963). Dynamics of bone remodeling. Springfield: Charles C. Thomas.

Frost, H. M. (1987a). Secondary osteon populations: An algorithm for determining mean bone tissue age. Yearbook of Physical Anthropology, 30, 221-238.

Frost, H. M. (1987b). Secondary osteon populations: An algorithm for estimating the missing osteons. Yearbook of Physical Anthropology, 30, 239-254

Frost, H. M. (1987c). Bone "mass" and the "mechanostat": A proposal. Anatomical Record, 219, 1-9.

Frost, H. M., \& Wu, K. (1967). Histological measurement of bone formation rates in unlabeled contemporary, archeological and paleontological compact bone. Miscellaneous Papers in Paleopathology. Technical Series, 7, 9-22.

Fuller, B., Molleson, T., Harris, D., Gilmour, L., \& Hedges, R. (2006). Isotopic evidence for breastfeeding and possible adult dietary differences from late/sub-Roman Britain. American Journal of Physical Anthropology, 129, 45-54. 
Gale, C. R., Martyn, C. N., Kellingray, S., Eastell, R., \& Cooper, C. (2001). Intrauterine programming of adult body composition. Journal of Clinical Endocrinology and Metabolism, 86, 267-272.

Garn, S. M. (1970). The earlier gain and the later loss of cortical bone, in nutritional perspective. Springfield: Thomas.

Garnsey, P. (1998). Cities, peasants and food in classical antiquity. Cambridge: Cambridge University Press.

Garnsey, P. (1999). Food and society in classical antiquity. Cambridge: Cambridge University Press.

Garnsey, P., \& Saller, R. (1987). The Roman Empire: Economy, society and culture (1st ed.). Berkeley: University of California Press.

Glencross, B., \& Agarwal, S. C. (2011). An investigation of cortical bone loss and fracture patterns in the neolithic community of Çatalhöyük, Turkey using metacarpal radiogrammetry. Journal of Archaeological Science, 38, 513-521.

Gosman, J. H., Stout, S. D., \& Larsen, C. S. (2011). Skeletal biology over the life span: A view from the surfaces. American Journal of Physical Anthropology, 146, 86-98.

Greco, E. (1975). Velia e Palinuro: problemi di topografia antica. Mélanges de l'École française de Rome. Antiquité, 87, 81-142.

Greco, E., \& Schnapp, A. (1986). Fortification et emprise du territoire: le cas de Velia. In P. Leriche, \& H. Treziny (Eds.) La fortification dans I'Histoire du monde grec. Actes du colloque international: La fortification et sa place dans l'histoire politique, culturelle et sociale du monde grec (pp. 209-212). Paris: Valbonne.

Greco, G. (1999). Velia: cittàdelle acque. In F. Krinzinger, \& G. Tocco (Eds.), Akten des ongresses "la ricerca archeologica a velia" (pp. 73-84). Vienna: Austrian Academy of Sciences Press.

Grynpas, M. D. (2003). The role of bone quality on bone loss and bone fragility. In S. C. Agarwal, \& S. D. Stout (Eds.) Bone loss and osteoporosis: An anthropological perspective (pp. 33-46). New York: Kluwer Plenum Academic Press.

Haara, M., Heliövaara, M., Impivaara, O., Arokoski, J. P. A., Manninen, P., Knekt, P., ... Kröger, H. (2006). Low metacarpal index predicts hip fracture: A prospective population study of 3,561 subjects with 15 years of follow-up. Acta Orthopaedica, 77, 9-14.

Harrigan, T. P., \& Mann, R. W. (1984). Characterization of microstructural anisotropy in orthotropic materials using a second rank tensor. Journal of Material Science, 19, 761-767.

Harlow, M., \& Laurence, R. (2002). Growing up and growing old in Ancient Rome: A life course approach. London: Routledge.

Heaney, R. (2003). Is the paradigm shifting? Bone, 33, 457-465.

Henderson, P. H., III, Sowers, M., Kutzko, K. E., \& Jannausch, M. L. (2000). Bone mineral density in grand multiparous women with extended lactation. American Journal of Obstetrics and Gynecology, 182, 1371-1377.

Hildebrand, T., \& Ruegsegger, P. (1997). A new method for the modelindependent assessment of thickness in three-dimensional images. Journal of Microscopy, 185, 67-75.

Hillier, T. A., Rizzo, J. H., Pedula, K. L., Stone, K. L., Cauley, J. A., Bauer, D. C., \& Cummings, S. R. (2003). Nulliparity and fracture risk in older women: The study of osteoporotic fractures. Journal of Bone Mineral Research, 18, 893-899.

Holck, P. (2007). Bone mineral densities in the prehistoric, Viking-Age and medieval populations of Norway. International Journal Osteoarchaeology, 17, 199-206.

isşcan, M., Loth, S., \& Wright, R. (1984). Age estimation from the rib by phase analysis: White males. Journal of Forensic Sciences, 29, 1094-1104.

Işcan, M., Loth, S., \& Wright, R. (1985). Age estimation from the rib by phase analysis: White females. Journal of Forensic Sciences, 30, 853-863.
Ives, R. \& Brickley, M. (2004). A procedural guide to metacarpal radiogrammetry in archaeology. International Journal of Osteoarchaeology, 14, 7-17.

Ives, R., \& Brickley, M. (2005). Metacarpal radiogrammetry: A useful indicator of bone loss throughout the skeleton? Journal of Archaeological Science, 32, 1552-1559.

Ives, R., Mant., de la Cova, C., \& Brickley, M. (2017). A large scale palaeopathological study of hip fractures from Post Medieval Urban England. International Journal of Osteoarchaeology, 27(2), 261-275.

Jackes, M. (2000). Building the bases for paleodemographic analyses: Adult age determination. In M. A. Katzenberg, \& S. R. Saunders (Eds.), Biological anthropology of the human skeleton (pp. 417-466). New York: Wiley Press.

Jackes, M. (2011). Representativeness and bias in archaeological skeletal samples. In S. C. Agarwal, \& B. Glencross (Eds.), Social bioarchaeology (pp. 417-466). Chichester: Wiley-Blackwell.

Janz, K. F., Letuchy, E. M., Burns, T. L., Eichenburger Gilmore, J. M., Torner, J. C., \& Levy, S. M. (2014). Objectively measured physical activity trajectories predict adolescent bone strength: lowa Bone Developmental Study. British Journal of Sports Medicine, 48, 1032-1036.

Kehoe, T. (2006). Bone quality: A perspective from the food and drug administration. Current Osteoporosis Reports, 4(2), 76-79.

Kneissel, M., Roschger, P., Steiner, W., Schamall, D., Kalchhauser, G., Boyde, A., \& Teschler-Nicola, M. (1997). Cancellous bone structure in the growing and aging lumbar spine in a historic Nubian population. Calcified Tissue International, 61, 95-100.

Kojima, N., Douchi, T., Kosha, S., \& Nagata, Y. (2002). Cross-sectional study of the effects of parturition and lactation on bone mineral density later in life. Maturitas, 41, 203-209.

Larsen, C. S. (2002). Bioarchaeology: The lives and lifestyles of past people. Journal of Archaeological Research, 10, 119-166.

Lazenby, R. A. (2002). Circumferential variation in human second metacarpal cortical thickness: Sex, age, and mechanical factors. Anatomical Record, 267, 154-158.

Lees, B., Molleson, T., Arnett, T. R., \& Stevenson, J. C. (1993). Differences in proximal femur bone density over two centuries. Lancet, 341, 673-675.

Leftkowitz, M. R., \& Fant, M. B. (1982). Women's life in Greece and Rome. London: Duckworth.

Lenora, J., Lekamwasam, S., \& Karlsson, M. K. (2009). Effects of multiparity and prolonged breast-feeding on maternal bone mineral density: A community-based cross-sectional study. BMC Women's Health, 9, 19.

Lipps, A. (2014). The role of female reproductive history in determining variation in cortical bone remodeling and trabecular architecture in a nonhuman animal model (Papio hamadryas) (Doctoral Dissertation). UC, Berkeley.

Lovejoy, C. O. (1985). Dental wear in the Libben population: Its functional pattern and role in the determination of adult skeletal age at death. American Journal of Physical Anthropology, 68, 47-56.

Lovejoy, C. O., Meindl, R. S., Pryzbeck, T. R., \& Mensforth, R. P. (1985). Chronological metamorphosis of the auricular surface of the ilium: A new method for the determination of adult skeletal age at death. American Journal of Physical Anthropology, 68, 15-28.

Madimenos, F. C. (2015). An evolutionary and life-history perspective on osteoporosis. Annual Review of Anthropology, 44, 189-206.

Maggio, D., Pacifici, R., Cherubini, A., Simonelli, G., Luchetti, M., Aisa, M. C., ... Senin, U. (1997). Age-related cortical bone loss at the metacarpal. Calcified Tissue International, 60, 94-97.

Martin, R. B. (2003). Functional adaptation and fragility of the skeleton. In S. C. Agarwal, \& S. D. Stout (Eds.), Bone loss and osteoporosis: 
An anthropological perspective (pp. 121-136). New York: Kluwer Plenum Academic Press.

Martin, R. B., \& Burr, D. B. (1989). Structure, function, and adaptation of compact bone. New York: Raven Press.

Martin, R. B., Burr, D. B., \& Sharkey, N. A. (1998). Skeletal tissue mechanics. New York: Springer-Verlag.

Marzano, A. (2007). Fish salting versus fish breeding: The case of Roman Italy. British Archaeological Reports International Series, 1686, 301-313.

Mays, S. (1998). Osteoporosis in earlier human populations. Journal of Clinical Densitometry, 2, 71-78.

Mays, S. (2000). Age-dependent cortical bone loss in women from 18th and early 19th century London. American Journal of Physical Anthropology, 112, 349-361.

Mays, S. (2001). Effects of age and occupation on cortical bone in a group of 18th-19th century British men. American Journal of Physical Anthropology, 116, 34-44.

Mays, S. (2006). Age-related cortical bone loss in women from a 3rd-4th century AD population from England. American Journal of Physical Anthropology, 129, 518-528.

Mays, S. (2010). The effects of infant feeding practices on infant and maternal health in a Medieval community. Childhood in the Past: An International Journal, 3(1), 63-78.

Mays, S. A. (1996). Age-dependent cortical bone loss in a medieval population. International Journal of Osteoarchaeology, 6, 144-154.

Mays, S., Turner-Walker, G., \& Syversen, U. (2006). Osteoporosis in a population from Medieval Norway. American Journal of Physical Anthropology, 131, 343-351.

Meema, H., \& Meema, S. (1987). Postmenopausal osteoporosis: Simple screening method for diagnosis before structural failure. Radiology, 164, 405-410.

Melsen, F., \& Mosekilde, L. (1981). The role of bone biopsy in the diagnosis of metabolic bone disease. The Orthopedic Clinics of North America, 12, 571-602.

Melton, L. J. (2003). Adverse outcomes of osteoporotic fractures in the general population. Journal of Bone and Mineral Research, 18(6), 1139-1141.

Michaëlsson, K., Baron, J. A., Farahmand, B. Y., \& Ljunghall, S. (2001). Influence of parity and lactation on hip fracture risk. American Journal of Epidemiology, 153, 1166-1172.

Milner, G. R., Wood, J. W., \& Boldsen, J. L. (2008). Paleodemography. In M. Katzenberg, \& S. Saunders (Eds.), Biological anthropology of the human skeleton (2nd ed., pp. 561-600). New York: Wiley-Liss.

Montalbán, S. J., Rico, L. H., Cortés, P. J., \& Pedrera Zamorano, J. D. (2001). Cortical bone mass and risk factors for osteoporosis among postmenopausal women in our environment. Revista Clínica Espanola, 201, 16-20.

Morel, J. P. (1999). Hyélè revue à la lumière de Massalia. In F. Krinzinger, \& G. Tocco (Eds.), Neue forschungen in velia (pp. 11-22). Vienna: Osterreichische Akademie der Wissenschaften.

Morris-Naumann, F. L., \& Wark, J. D. (2014). Exercise, Nutrition, and Bone Health. In M. F. Holick, \& J. W. Nieves (Eds.), Nutrition and health (pp. 543-560). New York: Springer.

Mosekilde, L. (1988). Age-related changes in vertebral trabecular bone architecture-Assessed by a new method. Bone, 9, 247-250.

Mulhern, D. (2000). Rib remodeling dynamics in a skeletal population from Kulubnarti, Nubia. American Journal of Physical Anthropology, 111, 519-530.

Mundy, G. (1995). Bone remodeling and its disorders. London: Martin Dunitz

Nelson, D. A., Sauer, N. J., \& Agarwal, S. C. (2003). Evolutionary aspects of bone health. Clinical Reviews in Bone and Mineral Metabolism, 1(3), 1-11.
Nicholson, P. H. F., Cheng, X. G., Lowet, G., Boonen, S., Davie, M. W. J., Dequeker, J., \& Van der Perre, G. (1997). Structural and material mechanical properties of human vertebral cancellous bone. Medical Engineering and Physics, 19(8), 729-737.

Nielsen, S. P. (2001). The metacarpal index revisited: A brief overview. Journal of Clinical Densitometry, 4, 199-207.

(NOF) National Osteoporosis Foundation. (2010). Available from: http:// www.nof.org/(cited February (2017).

Nordin, B. E. C., Chatterton, B. E., Schultz, C. G., Need, A. G., \& Horowitz, M. (1996). Regional bone mineral density interrelationships in normal and osteoporotic postmenopausal women. Journal of Bone and Mineral Research, 11, 849-856.

Njeh, C. F., Cheng, X. G., Elliot, J. M., \& Meunier, P. J. (1999). Bone, bone diseases, and bone quality. In C. F. Njeh, D. Hans, T. Fuerst, C. C. Gluer, \& H. K. Genant (Eds.), Quantitative ultrasound: Assessment of osteoporosis and bone status (pp. 1-20). London: Martin Dunitz.

Odgaard, A., \& Gundersen, H. (1993). Quantification of connectivity in cancellous bone, with special emphasis on 3-D reconstructions. Bone, $14,173-182$

Orwoll, E. S., Belknap, J. K., \& Klein, R. F. (2001). Gender specificity in the genetic determinants of peak bone mass. Journal of Bone and Mineral Research, 16(1), 1962-1971.

Parfitt, A. M., Drezner, M. K., Glorieux, F. H., Kanis, J. A., Malluche, H., Meunier, P. J., ... Recker, R. R. (1987). Bone histomorphometry: Standardization of nomenclature, symbols, and units. Journal of Bone and Mineral Research, 2, 595-610.

Parfitt, A. M., Han, Z. H., Palnitkar, S., Rao, D. S., Shih, M. S., \& Nelson, D. (1997). Effects of ethnicity and age or menopause on osteoblast function, bone mineralization, and osteoid accumulation in iliac bone. Journal of Bone Mineral Research, 12, 1864-1873.

Parfitt, A. M., Mathews, C. H. E.; Villanueva, A. R., Kleerekoper, A., Frame, B., \& Rao, D. S. (1983). Relationships between surface, volume and thickness of iliac trabecular bone in aging and in osteoporosis. Journal of Clinical Investigation, 72, 1396-1409.

Parfitt, M. (2003). New concepts of bone remolding: A unified spatial and temporal model with physiologic and pathophysiologic implications. In S. C. Agarwal, \& S. D. Stout (Eds.), Bone loss and osteoporosis: An anthropological perspective (pp. 3-15). New York: Kluwer Plenum Academic Press.

Paton, L. M., Alexander, J. L., Nowson, C. A., Margerison, C., Frame, M. G., Kaymakci, B., \& Wark, J. D. (2003). Pregnancy and lactation have no long-term deleterious effect on measures of bone mineral in healthy women: A twin study. American Society of Clinical Nutrition, 77(3), 707-714.

Pearson, O. M., \& Lieberman, D. E. (2004). The aging of Wolff's "law": Ontogeny and responses to mechanical loading in cortical bone. American Journal of Physical Anthropology, S39, 63-99.

Peck, J. J., \& Stout, S. D. (2007). Intraskeletal variability in bone mass. American Journal of Physical Anthropology, 132, 89-97.

Pfeiffer, S. K. (1998). Variability in osteon size in recent human populations. American Journal of Physical Anthropology, 106, 219-227.

Pfeiffer, S., Crowder, C., Harrington, L., \& Brown, M. (2006). Secondary osteon and Haversian canal dimensions as behavioral indicators. American Journal of Physical Anthropology, 131, 460-468.

Pfeiffer, S. K., \& Pinto, D. (2012). Histological examination of human bone in archaeological contexts. In C. Crowder, \& S. Stout (Eds.), Bone histology: An anthropological perspective (pp. 297-312). Boca Raton: CRC Press.

Prowse, T. L., Saunders, S. R., Schwarcz, H. P., Garnsey, P., Macchiarelli, R., \& Bondioli, L. (2008). Isotopic and dental evidence for infant and 
young child feeding practices in an Imperial Roman skeletal sample. American Journal of Physical Anthropology, 137, 294-308.

Qiu, A., Rao, D. S., Palnitkar, S. J., \& Parfitt, A. M. (2009). Dependence of bone yield (volume of bone formed per unit of cement surface area) on resorption cavity size during osteonal remodeling in human rib: Implications for osteoblast function and the pathogenesis of age-related bone loss. Journal of Bone and Mineral Research, 25(2), 423-430.

Raisz, L., \& Seeman, E. (2001). Causes of Age-related bone loss and bone fragility: An alternative view. Journal of Bone and Mineral Research, 16(1), 1948-1952.

Rauch, F. (2005). Bone growth in length and width: The Yin and Yang of bone stability. Journal of Musculoskeletal and Neuronal Interactions, 5, 194.

Rauch, F. (2007). Bone accrual in children: Adding substance to surfaces. Pediatrics, 119, s137-s140.

Rauch, F., Bailey, D. A., Baxter-Jones, A., Mirwald, R., \& Faulkner, R. (2004). The "muscle-bone unit" during the pubertal growth spurt. Bone, 34, 771-775.

Redfern, R. (2007). The infleunce of culture upon childhood: An osteological study of Iron Age and Romano-British Dorset. In M. Harlow, \& R. Laurence (Eds.), Age and ageing in the Roman Empire (pp. 171194). Portsmouth: Journal of Roman Archaeology.

Reed, M. R., Murray, J. R. D., Abdy, S. E., Francis, R. M., \& McCaskie, A. $W$. (2004). The use of digital $X$-ray radiogrammetry and peripheral dual energy $\mathrm{X}$-ray absorptiometry in patients attending fracture clinic after distal forearm fracture. Bone, 34, 716-719.

Ridler, T. W. (1978). Picture thresholding using an iterative selection method. IEEE Transactions on Systems, Man, and Cybernetics, 8(8), 630-632.

Riggs, B. L., Melton, L. J., Robb, R. A., Camp, J. J., Atkinson, E. J., McDaniel, L., ... Khosla, S. (2008). A population-based assessment of rates of bone loss at multiple skeletal sites: Evidence for substantial trabecular bone loss in young adult women and men. Journal of Bone and Mineral Research, 23, 205-214.

Robling, A. G., \& Stout, S. D. (2000). Histomorphometry of human cortical bone: Applications to age estimation. In M. A. Katzenburg, \& S. R. Saunders (Eds.), Biological anthropology of the human skeleton (pp. 187-214). New York: Wiley-Liss.

Robling, A. G., \& Stout, S. D. (2003). Histomorphology, geometry, and mechanical loading in past populations. In S. C. Agarwal, \& S. D. Stout (Eds.), Bone loss and osteoporosis: An anthropological perspective (pp. 184-201). New York: Kluwer Plenum Academic Press.

Roschger, P., Grabner, B. M., Rinnerthaler, S., Tesch, W., Kneissel, M., Berzlanovich, A., ... Fratz, P. (2001). Structural development of the mineralized tissue in the human L4 vertebral body. Journal of Structural Biology, 136, 126-136.

Rosholm, A., Hyldstrup, L., Backsgaard, L., Grunkin, M., \& Thodberg, H. H. (2001). Estimation of bone mineral density by digital X-ray radiogrammetry: Theoretical background and clinical testing. Osteoporosis International, 12, 961-969.

Ross, P. D., Santora, A., \& Yates, A. J. (1999). Epidemiology and consequences of osteoporotic fractures. In G. J. Rosen, J. Glowacki, \& J. P. Bilezikian (Eds.), The aging skeleton (pp. 339-347). San Diego: Academic Press.

Roux, J. P., Wegrzyn, J., Arlot, M. E., Guyen, O., Delmas, P. D., Chapurlat R., \& Bouxsein, M. L. (2010). Contribution of trabecular and cortical components to biomechanical behavior of human vertebrae: An ex vivo study. Journal of Bone and Mineral Research, 25(2), 356-361.

Ruff, C., Holt, B., \& Trinkaus, E. (2006). Who's Afraid of the Big Bad Wolff?: "Wolff's Law" and Bone Functional Adaptation. American Journal of Physical Anthropology, 129, 484-498.
Ryan, T. M., \& Shaw, C. N. (2015). Gracility of the modern Homo sapiens skeleton is the result of decreased biomechanical loading. Proceedings of the National Academy of Sciences United States of America, 112, 372-377.

Scheidel, W. (1996). The most silent women of Greece and Rome: Rural labour and women's life in the Ancient World (II). Greece \& Rome, 43, 1-10.

Schmeidt, G. (1970). Contributo alla ricostruzione della situazione geotopografica di Velia nell'Antichita. Parola Passato, 25, 65-92.

Schoenau, E., Fricke, O., \& Rauch, F. (2003). The regulation of bone development as a biological system. Homo, 54(2), 113-118.

Schultz, M. (2001). Paleohistopathology of bone: A new approach to the study of ancient diseases. Yearbook of Physical Anthropology, 44 106-147.

Seeman, E. (1996). The effects of tobacco and alcohol use on bone. In R. Marcus, D. Feldman, \& J. Kelsey (Eds.), Osteoporosis (pp. 577-597). San Diego: Academic Press.

Seeman, E. (2002). Pathogenesis of bone fragility in women and men The Lancet, 359, 1841-1850.

Seeman, E. (2007). The periosteum-A surface for all seasons. Osteoporosis International, 18, 123-128.

Sigismund-Nielsen, H. (2007). Children for profit and pleasure. In M. Harlow, \& R. Laurence (Eds.), Age and ageing in the Roman empire (pp. 37-54). Portsmouth: Journal of Roman Archaeology.

Snyder, B. D., Piazza, S., Edwards, W. T., \& Hayes, W. C. (1993). Role of trabecular morphology in the etiology of age-related vertebral fractures. Calcified Tissue International, 53(Suppl 1), S14-S22.

Sobelman, O. S., Gibeling, J. C., Stover, S. M., Hazelwood, S. J., Yeh, O C., Shelton, D. R., \& Martin, R. B. (2004). Do microcracks decrease or increase fatigue resistance in cortical bone? Journal of Biomechanics, 37(1), 295-1303.

Sornay-Rendu, E., Boutroy, S., Munoz, F., \& Bouxsein, M. L. (2009). Cortical and trabecular architecture are altered in postmenopausal women with fractures. Osteoporosis International, 20, 1291-1297.

Sowers, M. (1996). Pregnancy and lactation as risk factors for subsequent bone loss and osteoporosis. Journal of Bone Mineral Research, 11, 1052-1060.

Stein, M. S., Feik, S. A., Thomas, C. D. L., Clement, J. G., \& Wark, J. D. (1999). An automated analysis of intracortical porosity in human femoral bone across age. Journal of Bone and Mineral Research, 14(4), 624-632.

Stevenson, J. C., Macintyre, I., Banks, M., Freemantle, C., Spinks, T., Hesp, R., ... Whitehead, M. I. (1986). Regional specificity of bone measurements in postmenopausal women. Bone, 7, 147-148.

Stini, W. A. (1995). Osteoporosis in biocultural perspective. Annual Review of Anthropology, 24, 397-421.

Stout, S. D., \& Lueck, R. (1995). Bone remodeling rates and skeletal maturation in three archaeological skeletal populations. American Journal of Physical Anthropology, 98, 161-171.

Stout, S. D., \& Paine, R. E. (1994). Brief communication: Bone remodeling rates: A test of an algorithm for estimating missing osteons. American Journal of Physical Anthropology, 93, 123-129.

Stout, S. D., \& Teitelbaum, S. L. (1976). Histological analysis of undecalcified thin sections of archaeological bone. American Journal of Physical Anthropology, 44, 263-270.

Szulc, P., Seeman, E., Duboeuf, F., Sornay-Rendu, E., \& Delmas, P. D. (2006). Bone fragility: Failure of periosteal apposition to compensate for increased endocortical resorption in postmenopausal women. Journal of Bone and Mineral Research, 21, 1856-1863.

Takahashi, H., \& Frost, H. M. (1964). The kinetics of the resorption process in osteonal remodeling of diabetic ribs. Henry Ford Hospital Medical Bulletin, 12, 537-545. 
Takahashi, H., \& Frost, H. M. (1966). Age and sex related changes in the amount of cortex of normal human ribs. Acta Orthopaedica Scandinavica, 37, 122-130.

Thomsen, J. S., Ebbesen, E. N., \& Mosekilde, L. (2002). Age-related differences between thinning of horizontal and vertical trabeculae in human lumbar bone as assessed by a new computerized method. Bone, 31, 136-142

Toner, J. (2002). Rethinking Roman history. Cambridge: Oleander Press.

Toner, J. (2009). Popular culture in ancient Rome. Cambridge: Polity.

Twomey, L., Taylor, J., \& Furniss, B. (1983). Age changes in the bone density and structure of the lumbar vertebral column. Journal of Anatomy, 136, 15-25.

Van Oers, R. F. M., Ruimerman, R., van Rietbergen, B., Hilbers, P. A. J., \& Huiskes, R. (2008). Relating osteon diameter to strain. Bone, 43, 476-482.

Virtama, P., \& Helelä, T. (1969). Radiographic measurements of cortical bone: Variation in a normal population between 1 and 90 years of age. Acta Radiologica, S293, 1-268.

Vogel, M., Hahn, M., Caselitz, P., Woggan, J., Pompesius-Kempa, M., \& Delling, G. (1990). Comparison of trabecular bone structure in man today and an ancient population in Western Germany. In H. E. Takahashi (Ed.), Bone morphometry (pp. 220-223). Japan: Nishimura Co.

Weaver, D. S. (1998). Osteoporosis in the bioarchaeology of women. In A Grauer, \& P. Stuart-Macadam (Eds.), Sex and gender in paleopathological perspective (pp. 27-46). Cambridge: Cambridge University Press.

Wegrzyn, J., Roux, J. P., Arlot, M. E., Boutroy, S., Vilayphiou, N., Guyen, O., ... Bouxsein, M. L. (2010). Role of trabecular microarchitecture and its heterogeneity parameters in the mechanical behavior of ex vivo L3 vertebrae. Journal of Bone and Mineral Research, 25(11), 2324-2331.

Wiklund, P. K., Xu, L., Wang, Q., Mikkola, T., Lyytikäinen, A., Völgyi, E., ... Cheng, S. (2011). Lactation is associated with greater maternal bone size and bone strength later in life. Osteoporosis International, 23(7), 1939-1945.

Wood, J. W., Milner, G. R., Harpending, H. C., Weiss, K. M., Cohen, M. N., Eisenberg, L. E., ... Wilkinson, R. G. (1992). The Osteological Paradox: Problems of inferring prehistoric health from skeletal samples. Current Anthropology, 33, 343-370.

Wright, L. E., \& Yoder, C. J. (2003). Recent progress in bioarchaeology: Approaches to the osteological paradox. Journal of Archaeological Research, 11(1), 44-70.

Wu, K., Schubeck, K. E., Frost, H., \& Villanueva, A. (1970). Haversian bone formation rates determined by a new method in a mastodon, and in human diabetes mellitus and osteoporosis. Calcified Tissue Research, 6, 204-219.

How to cite this article: Beauchesne P, Agarwal SC. A multi-method assessment of bone maintenance and loss in an Imperial Roman population: Implications for future studies of age-related bone loss in the past. Am J Phys Anthropol. 2017;164:41-61. https://doi.org/10.1002/ajpa.23256 